Portland State University

PDXScholar

6-5-1995

\title{
Teaching English Grapheme-Phoneme Correspondences to Chinese Students
}

Li-ching Lin

Portland State University

Follow this and additional works at: https://pdxscholar.library.pdx.edu/open_access_etds

Part of the Bilingual, Multilingual, and Multicultural Education Commons Let us know how access to this document benefits you.

\section{Recommended Citation}

Lin, Li-ching, "Teaching English Grapheme-Phoneme Correspondences to Chinese Students" (1995). Dissertations and Theses. Paper 5027.

https://doi.org/10.15760/etd.6903

This Thesis is brought to you for free and open access. It has been accepted for inclusion in Dissertations and Theses by an authorized administrator of PDXScholar. Please contact us if we can make this document more accessible: pdxscholar@pdx.edu. 
THESIS APPROVAL

The abstract and thesis of Li-ching Lin for the Master of Arts in TESOL were presented June 5,1995 , and accepted by the thesis committee and the department.

COMMITTEE APPROVALS:

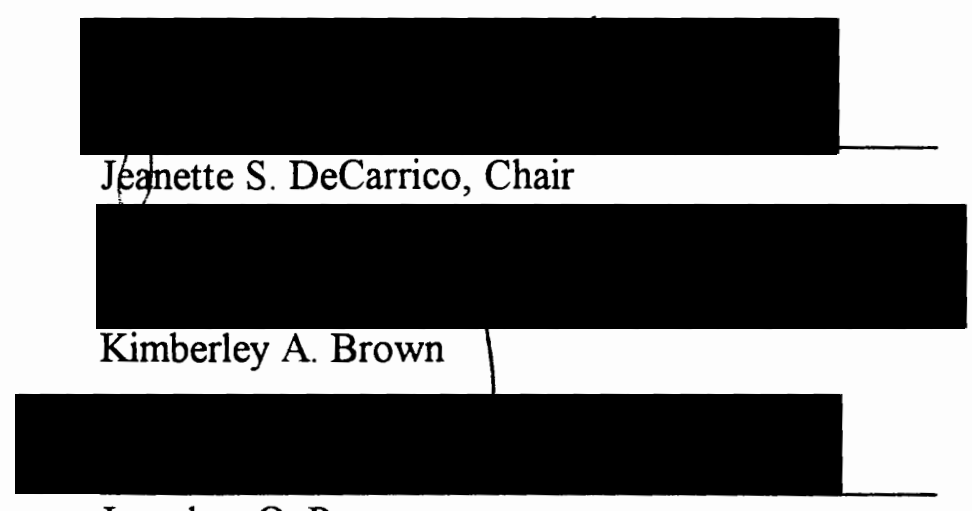

Jonathan O. Pease

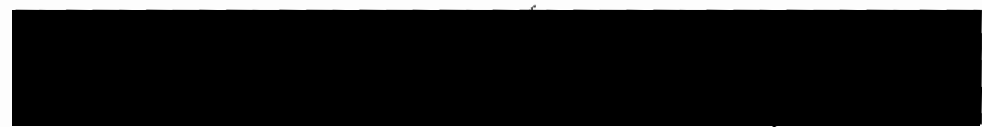

Elaine E. Limbaugh

Representative of the Office of Graduate Studies

DEPARTMENT APPROVAL:

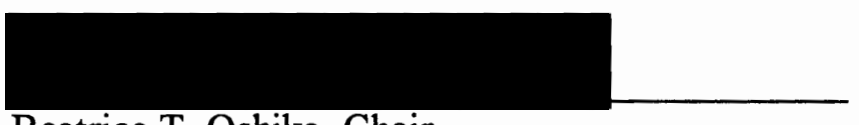

Beatrice T. Oshika, Chair

Department of Applied Linguistics

ACCEPTED FOR PORTLAND STATE UNIVERSITY BY THE LIBRARY by on 19 lectakex 1995 


\begin{abstract}
An abstract of the thesis of Li-ching Lin for the Master of Arts in TESOL presented June 5, 1995.

Title: Teaching English Grapheme-Phoneme Correspondences to Chinese Students.

This study investigates whether or not instruction of English graphophonic correspondences, i.e., the link between letters and sounds, will help Chinese students in learning English vocabulary. Following other related research, I assume that Chinese students can benefit from instruction of English grapheme-phoneme correspondences in learning English words. If this assumption is true, there should be a statistically significant difference between students who have instruction of English graphophonic correspondences for learning English words and students who do not.
\end{abstract}

1. Chinese students who have been given lessons in both pronunciation and grapheme-phoneme correspondences will recall more English words on a short-term vocabulary test immediately after a vocabulary learning session than will the students who have been given only the lessons in pronunciation.

2. Chinese students who have been given lessons in both pronunciation and grapheme-phoneme correspondences will also recall more English words on a long-term vocabulary test two weeks after a vocabulary learning session than will the students who have been given only the lessons in pronunciation.

Two groups of students who are in their second year of a junior college in Taiwan participated in this study. The control group was given the normal English course and pronunciation course which did not include the instruction of any letter-sound relationships. The experimental group was given not only the normal English course and pronunciation practice but also instruction in English graphophonic correspondences. This research examined whether or not the students given explicit instruction in English 
graphophonic correspondences had better performance on both short-term and long-term vocabulary recall tests after the special instruction.

The experimental group recalled more words on both short-term and long-term vocabulary recall tests. Moreover, they behaved differently across time depending on which group they were in: The experimental group's performance continued to progress over time while the control group's performance fluctuated across time. The data collected during the experiment support both hypotheses. 


\title{
TEACHING ENGLISH GRAPHEME-PHONEME CORRESPONDENCES TO CHINESE STUDENTS
}

\author{
by \\ LI-CHING LIN
}

A thesis submitted in partial fulfillment of the

requirements for the degree of

MASTER OF ARTS

in

TESOL

Portland State University

1995 
To my family 


\section{ACKNOWLEDGMENTS}

First of all, I would like to thank my thesis adviser, Professor Jeanette DeCarrico, for what she did to help me finish this thesis. I would especially like to acknowledge Professor Jonathan Pease for his inspiring ideas and the hours he spent working with me. In addition, I want to thank Professor Kimberley Brown, who always gave me crucial academic suggestions and comments, and Professor Elaine Limbaugh for her pep talks and support.

I also want to express my thanks to Jonathan Falk for his help in proofreading all my writing, and to Ting Xiong for his computer assistance, and to Jay Peterson for his suggestions and help in statistics. Finally, I would like to recognize my friend, Jin-Jung Fon, for letting me conduct my project in her school. Without her, this project would not have been realized. 


\section{TABLE OF CONTENTS}

CHAPTER

PAGE

ACKNOWLEDGMENTS ............................................................... ii

LIST OF TABLES ................................................................... vii

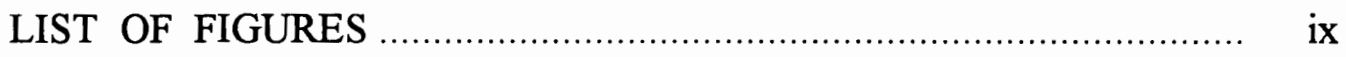

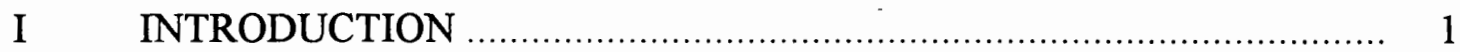

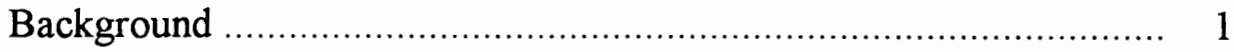

The Research Question .......................................................... 4

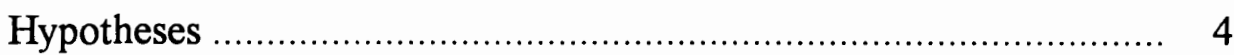

II REVIEW OF THE LITERATURE _................................................ 6

Chinese Orthography - the Logographic Writing System .................. 6

Simple Characters …............................................................. 8

Compound Characters ......................................................... 8

Character Sequences ….................................................. 10

Grapheme-Phoneme Correspondences in English Orthography ......... 12

Why Should Chinese Students Be Taught English Graphophonic Correspondences

English Graphophonic Correspondences Can Help Chinese

Students in Vocabulary Learning

English Graphophonic Correspondences Can Help Chinese

Students Pay Attention to Pronunciation

The Connections between Spelling and Meaning in English Orthography Can Help Chinese Students Develop Word Knowledge 
How to Teach Grapheme-Phoneme Correspondences .................... 18

Phonemic Awareness ........................................................ 18

Patterns from Symbols to Sounds ......................................... 19

Relationships between Spelling, Meaning and Sound ............... 19

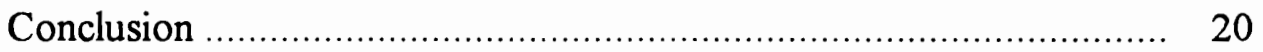

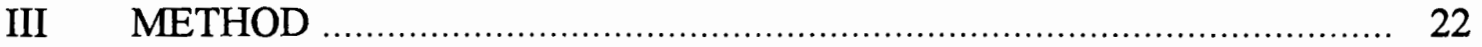

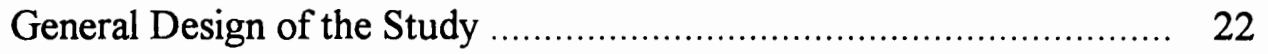

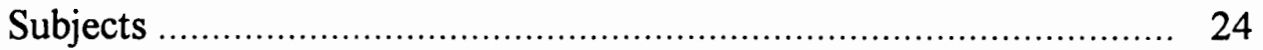

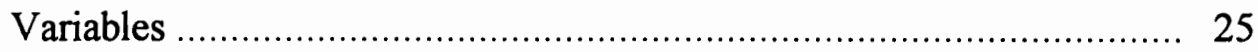

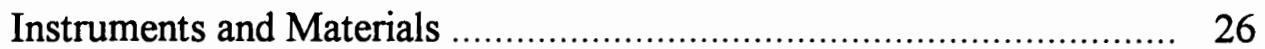

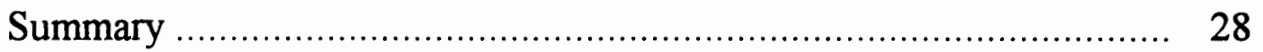

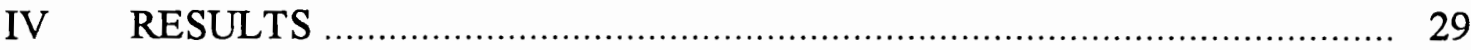

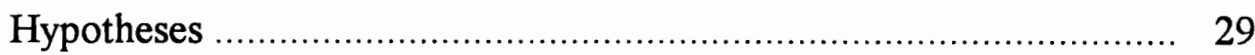

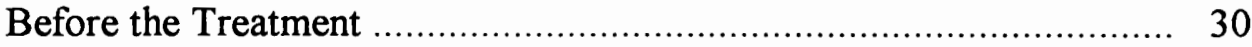

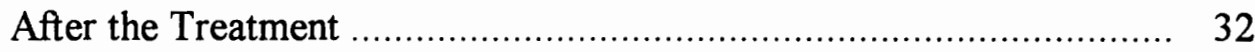

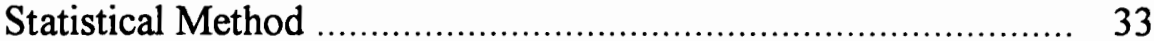

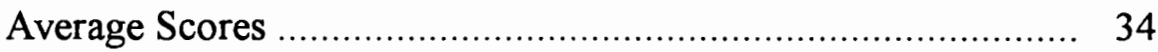

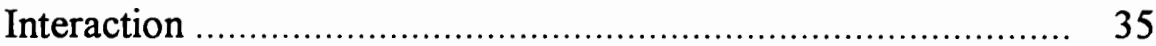

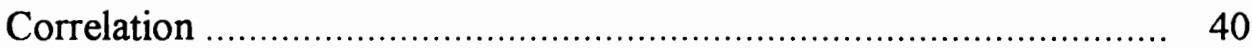

Statistical Method …........................................................... 40

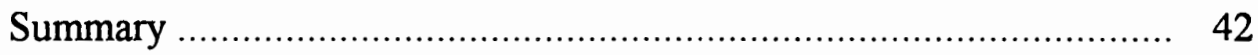

V DISCUSSION OF RESULTS ................................................... 44

Discussion of the Findings ........................................................... 44

Graphophonic Correspondences .......................................... 44

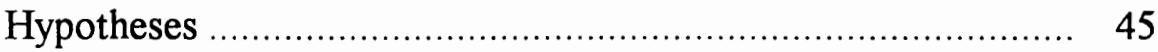


Correlation ........................................................ 46

Findings ........................................................... 46

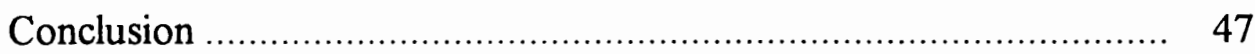

Implications for Teaching English Vocabulary to Chinese Students .... 48

Limitations and Methodological Problems ............................... 49

Suggestions for Further Research .................................... 50

REFERENCES ................................................................ 51

APPENDICES

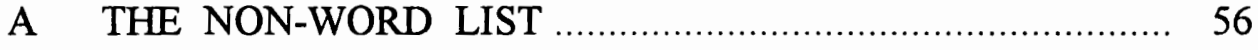

B THE CURRICULA (CONTROL) .............................. 58

C THE CURRICULA (EXPERIMENTAL) ........................ 83

D THE VOCABULARY LEARNING LIST ....................... 109

E THE SHORT-TERM AND LONG-TERM TESTS ........... 114

F THE WORD LIST FOR PRONUNCIATION TEST .......... 119

G THE INFORMED CONSENT FORM ......................... 121 


\section{LIST OF TABLES}

TABLE

PAGE

I t-test for the English Vocabulary Test before the Experiment

II t-test for the Non-Word Test before the Treatment

III t-test for the Short-Term Vocabulary Recall Test

IV t-test for the Long-Term Vocabulary Recall Test

V Summaries of Difference between the Non-Word Test and the Short-Term Test

VI Analysis of Variance of Difference across Time between the Non-Word Test and the Short-Term Test

VII Summaries of Difference between the Short-Term Test and the Long-Term Test

VIII Analysis of Variance of Difference across Time between the Short-Term Test and the Long-Term Test

IX The Correlation Coefficient between the Short-Term Test and the Pronunciation Test (all 21 students)

X The Correlation Coefficient between the Short-Term Test and the Pronunciation Test (11 students in the experimental group) ....... 
XI The Correlation Coefficient between the Short-Term Test and the Pronunciation Test (10 students in the control group) 


\section{LIST OF FIGURES}

FIGURE

PAGE

1. Chinese Symbol-Sound Correspondences ........................................... 7

2. Average Scores of the Control and Experimental Groups ........................ 38

3. Group $x$ Time Interaction between the Control and Experimental Groups ... 39 


\section{CHAPTER I}

\section{INTRODUCTION}

\section{BACKGROUND}

Languages may vary in the type of writing system used, in the degree of correspondence between symbols and sounds, and in the particular levels of phonological structure represented by the symbols. It is generally recognized that writing systems fall into two broad categories: logographic and alphabetic (Fromkin \& Rodman, 1988). Alphabetic systems are those in which each symbol (grapheme) ideally corresponds to one sound unit (phoneme). For writing purposes, therefore, each word to be recorded must be separated into the speech sounds of which it is composed. The symbols for those speech sounds are then set down in the same sequence in which they are produced in the spoken word (Balmuth, 1982). Therefore, an alphabetic system is basically graphophonic. In the Chinese writing system, however, the sound (phoneme) corresponds to the whole wordform, i.e. the character, rather than to segments, and individual component strokes of the written characters do not themselves represent aspects of the phonological pattern (Garman, 1990). Given this orthographic structure, there is no grapheme-phoneme correspondence rule in Chinese (Cheng, 1992). In contrast to alphabetic languages, pronouncing a Chinese character analytically through its component units (strokes) is impossible. In other words, the symbol-sound mappings do not become apparent until the character has been identified.

Some educators have begun to consider the overall effects on thinking due to processing distinctions signaled by the use of differing writing systems (e.g., Barnitz, 1982; Huang, 1992; Osborne-Wilson, Sinatra, \& Baratta, 1989; Zhou, 1988). After reviewing the clinical and experimental research, Zhou (1988) has concluded that the 
Chinese writing system is processed visually and holistically, and alphabetic writing systems are processed acoustically and analytically. For Chinese students, it is difficult to be aware of the stable patterns existing in the relationship between letters and sounds in an alphabetic language, such as English. This is because of the lack of a grapheme-phoneme correspondence characteristic in their first language. Without instruction in English graphophonic correspondences, Chinese students tend to transfer their familiar characterlearning strategies to learning English (Huang, 1992).

Many researchers claim that written words in an alphabetic system can be approached in a phonologically analytic fashion (e.g., Adams, 1990; Gleitman \& Rozin, 1977; Gough \& Hillinger, 1980; Liberman \& Shankweiler, 1979) or, alternatively, they can be learned and remembered holistically, i.e., as though they were logographs (e.g., Goswami \& Bryant, 1990). As Gough and Hillinger (1980) stress, the difficulty with the logographic strategy is that it is self-limiting because it does not enable a reader to read new words. Moreover, as the vocabulary grows and the number of visually similar words increases, the memory burden becomes severe and the logographic strategy becomes progressively more inaccurate in processing an alphabetic system.

Garman (1990) notes that English orthography seems to violate a very simple spelling-to-sound correspondence, but embodies a set of relationships that are considerably more sophisticated and carry a number of advantages. Many researchers have done studies which suggest phonological awareness is strongly related to success in beginning to read alphabetical languages (e.g., Bialystok, 1991; Byrne \& FieldingBarnsley, 1989; Cunningham, 1990; Yopp, 1992). Thus, those studies suggest that the sophisticated, rather than simple, correspondences between letters and sounds in English orthography should be taught explicitly, even to native speakers of English. Accordingly, these studies imply that the regularity of grapheme-phoneme correspondences in English needs to be taught to second language learners, especially those whose first language is logographic such as Chinese.

There is evidence from psychological research that asserts the role of phonological analysis (graphophonic analysis) in reading. It is claimed that phonological activation 
serves word identification, but that it also has an equally important and more universal function in comprehension (Perfetti, Zhang, \& Berent, 1992). Phonological word forms are part of the reader's short-term memory, and comprehension depends on this in several ways. First, there is what is called "reference securing" (Perfetti \& McCutchen, 1982), establishing memory representations that are specific enough to allow specific discourse referents to be accessed on demand. Semantic information abstracted from word forms is not enough. The functional difference between $d o g$ and canine is their distinct phonological forms, not their meanings. It is clear that readers in fact generally retain the exact wording for a sentence or at least a clause, just as listeners do (Goldman, Hogaboam, Bell, \& Perfetti, 1980).

There is also a confirmation of the role of sound (phonological representation) in second language comprehension and production. After reviewing some psycholinguistic research, Joanna Channell (1988) has pointed out that for second language learners semantic and phonological links would be the most helpful in facilitating the future recall of languages such as English. Another discovery was that these kinds of link between sound and meaning should be encouraged in presenting vocabulary to second language learners.

Despite the above evidence gained from research, English teachers in Taiwan do not pay attention to teaching pronunciation, not to mention graphophonic correspondences in English orthography. Many of them simply assume students can figure out the relationships between letters and sounds in the English writing system. It seems necessary to reconsider the assumption that students, especially second language learners such as Chinese students, can figure out the relationships between letters and sounds in English by themselves, i.e., that they can recode words without any training. The instruction in English graphophonic correspondences that I am talking about here is not a method which focuses on the set of rules establishing the relationship between sounds of letters and their names. It concerns, rather, knowledge about letter-sound relationships in English. I would like to give students graphophonic knowledge, that is, knowledge of letter-sound relationships which allows readers to verify predictions. I suspect that the 
regularity existing in English graphophonic correspondences needs to be taught to Chinese students to help them develop graphophonic strategies for learning English more effectively and efficiently.

\section{THE RESEARCH QUESTION}

This research investigated whether or not instruction in English graphophonic correspondences, i.e., the link between letters and sounds, will help Chinese students in learning English vocabulary. On the basis of the above discussion, I assumed that Chinese students could benefit from instruction in the link between English letters and sounds. If this assumption is true, there should be a statistically significant difference between students who have instruction in English graphophonic correspondences for learning English words and students who do not. If the assumption is not true, then there should be no statistically significant difference between these two groups of students.

There were two groups of 18-19 year old, second-year junior college students participating in this research. They have been learning English for more than four years. The control group was given the normal English course and pronunciation instruction which did not include any English letter-sound relationships. The experimental group was given not only the normal English course and pronunciation practice but also instruction in English graphophonic correspondences. This study examines whether or not the students given explicit instruction in English graphophonic correspondences performed better on both short-term and long-term vocabulary recall tests after the special instruction.

\section{HYPOTHESES}

In order to investigate the relative effectiveness of the instruction that Chinese students might benefit from on an experimental level, the research hypotheses were made as follows: 
1. Chinese students who have been given lessons in both pronunciation and grapheme-phoneme correspondences will recall more English words on a short-term vocabulary test immediately after a vocabulary learning session than will the students who have been given only the lessons in pronunciation.

2. Chinese students who have been given lessons in both pronunciation and grapheme-phoneme correspondences will also recall more English words on a long-term vocabulary test two weeks after a vocabulary learning session than will the students who have been given only the lessons in pronunciation.

I wanted to see whether or not these two hypotheses were supported in this research. If statistically significant differences in hypothesis 1 and 2 were found, it would support the claim that instruction in English graphophonic correspondences will help Chinese students learn English vocabulary better than the other way, which does not include teaching such correspondences. If these two hypotheses were not supported by the results at a statistically significant level, it would indicate that the instruction that I predicted Chinese students would benefit from is not superior to the other way. 


\section{CHAPTER II}

\section{REVIEW OF THE LITERATURE}

\section{CHINESE ORTHOGRAPHY-THE LOGOGRAPHIC WRITING SYSTEM}

Ancient Chinese characters were designed to directly represent objects and events rather than to represent speech sounds. However, modern Chinese characters evolved to represent speech sounds, while simultaneously continuing to represent objects and events ( $\mathrm{Li}, 1977)$. As is shown in Figure 1 in the following page (inspired by Cheng, 1992), the symbol-sound correspondences in Chinese are not rigid: visually identical or visually similar characters can be either phonologically identical or phonologically different, and so can visually dissimilar characters. Given this orthographic structure, Cheng (1992) claims that no grapheme-phoneme correspondence rules exist in Chinese.

Garman (1990, p. 28-31) demonstrates how phonological aspects are related to Chinese characters. There are basically three sorts of character to consider: simple characters, compound characters, and character sequences. 


\section{Chinese Symbol-Sound Correspondences}

\begin{tabular}{|l|c|l|}
\hline \multicolumn{1}{|c|}{ Pairing condition } & Visual & Auditory \\
\hline $\begin{array}{l}\text { Visually identical } \\
\text { phonologically identical }\end{array}$ & 別 (other) - 別 (don't) & bie - bie \\
\hline $\begin{array}{l}\text { Visually identical } \\
\text { phonologically similar }\end{array}$ & 樂 (music) - 樂 (happy) & yue - le \\
\hline $\begin{array}{l}\text { Visually identical } \\
\text { phonologically dissimilar }\end{array}$ & 惡 (evil) - 惡 (dislike) & e - wu \\
\hline $\begin{array}{l}\text { Visually similar } \\
\text { phonologically identical }\end{array}$ & 培 - 陪 & pei - pei \\
\hline $\begin{array}{l}\text { Visually similar } \\
\text { phonologically similar }\end{array}$ & 讀 - 續 & du - xu \\
\hline $\begin{array}{l}\text { Visually similar } \\
\text { phonologically dissimilar }\end{array}$ & 痕 - 退 & hen - tui \\
\hline $\begin{array}{l}\text { Visually dissimilar } \\
\text { phonologically identical }\end{array}$ & 那 - 納 & na - na \\
\hline $\begin{array}{l}\text { Visually dissimilar } \\
\text { phonologically similar }\end{array}$ & 補 - 譯 & bu - yi \\
\hline $\begin{array}{l}\text { Visually dissimilar } \\
\text { phonologically dissimilar }\end{array}$ & jian - qian \\
\hline
\end{tabular}

Figure 1 is inspired by C. M. Cheng (1992). 
Simple Characters

(1) 人

ren

person

(2) 木

$\mathrm{mu}$

tree

(3) 其

qi

his, her, its, etc.

The first two of these simple characters, 人 "person", 木 "tree", illustrate the simplest sort of meaning-based symbol, even preserving something of their_representational (pictographic) basis. Maybe the term "ideographic" will be more accurate. The third 其 "his/her/its" is representationally much more abstract, as well as being more complex in term of its component strokes; for this reason it may be called logographic, since there is no hint of an attempt here to portray the idea of the word, only to provide a distinct symbol for the word itself. Of all these characters there is no connection between their stroke structure and the sound structure of the words they represent: Nothing marks the tone or the phonemic sequence in any way; there is nothing graphophonic about them.

\section{Compound Characters}

These compound characters are of two major types, non-graphophonic and graphophonic. The first may be illustrated as follows:

Non-Graphophonic. There is graphological compositionality here, quite clearly; but it is not linked to any phonological relationship.

$\begin{array}{llll}\text { 木 } \\ \text { mu } \\ \text { tree }\end{array}+\begin{aligned} & \text { 木 } \\ & \text { mu } \\ & \text { tree }\end{aligned} \quad \begin{aligned} & \text { 林 } \\ & \text { lin } \\ & \text { woods }\end{aligned}$ or $\begin{aligned} & \text { 森en } \\ & \text { forest }\end{aligned}$


Note that a compound character is distinct from a character sequence, which will be discussed below: it may be graphologically complex in a fully compositional fashion, but it represents a single character.

Compound characters may also involve reduced forms of simple characters:

$\begin{aligned} & \text { 人 } \\ & \text { ren } \\ & \text { person }\end{aligned}+\underset{\text { mu }}{\text { tree }}=\begin{aligned} & \text { 休 } \\ & \text { xiu } \\ & \text { rest }\end{aligned}$

Here $T$ in the compound is the reduced form of $人$ ren: it functions in this compound as the radical, a type of element which will be talked about below. In each case, however, the symbol-to-sound relationship is abstract: xiu 休, lin 林, sen 森, etc. are all represented. by non-graphophonic symbols.

Graphophonic. A second type of compound has some graphophonic aspects:

$\begin{array}{lll}\text { 木 } & \text { 反 } \\ \text { mu } & +\quad \begin{array}{l}\text { fan } \\ \text { tree }\end{array} \quad \text { to turn over } & \text { ban } \\ \text { board }\end{array}$

$\begin{array}{lll}\text { 木 } & \text { 公 } \\ \mathrm{mu} & + \text { gong } \\ \text { tree } & \text { public }\end{array} \quad \begin{aligned} & \text { 松 } \\ & \text { song } \\ & \text { pine tree }\end{aligned}$

$\begin{array}{ll}\text { 竹 } \\ \text { zhu } \\ \text { bamboo }\end{array}+\begin{aligned} & \text { 監 } \\ & \text { jian } \\ & \text { prison }\end{aligned}=\begin{aligned} & \text { 籃 } \\ & \text { bamboo basket }\end{aligned}$

In (6) and (7), the leftmost element of the compound, 木, is called the radical (cf. also $T$ in 休 in (5)), and is not represented in the pronunciation of the word at all. It is typically representative of the meaning of the compound. The radical may appear in any position, not just on the left-for example, the 竹 in 籃 in (8). However, for any particular compound character, the position of the radical element is conventionally fixed: 
i.e. $\}$ in 休 and 竹 in 籃 cannot appear in any other position. The remaining element of these compounds serves the function of marking the phonological form of the word. The degree to which it achieves this may be less than absolute, as in (6), (7), and (8). But the graphophonic function of this element can be fully accurate just as in (9):

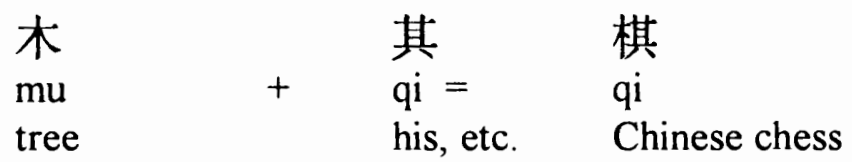

where the compound says "related to wood, and pronounced like qi".

\section{Character Sequences}

In practice, only a learner of the Chinese script would interpret 松 in (7) as "a sort of tree, and pronounced like gong". For a fluent reader, the character as a whole would map onto the lexical item \{song: "pine tree" . What this means is that the force of the radical component is frequently lost, and the result of this may be seen in the existence of certain character sequences such as (10):

$\begin{array}{ll}\text { 木 } & \text { 板 } \\ \text { mu } & \text { ban } \\ \text { tree } & \text { board }=\text { wooden board }\end{array}$

In (10) there is no new character formed, but rather a (syntactic) sequence of characters to express one meaning. But notice that the first character, the form of $m u$, is required to distinguish wooden from other types of board.

There are many words that consist of two or three characters

(a character sequence), so words are not always equivalent to characters in modern Chinese.

$$
\begin{aligned}
& \text { 學校 } \\
& \text { xuexiao } \\
& \text { school }
\end{aligned}
$$


(12)

茄子

qiezi

eggplant

(13)

油漆

youqi

paint

(14)
圖 書 館
tushuguan
library

Chao (1968) has claimed, "The Chinese sociological equivalent of the word is called 字 tzyh" (p. 136). (The “字 tzyh” is what in English is usually called a "character.") Although a character is sometimes not equal to a word, a written character always represents an entire syllable in Chinese. The fact that one character corresponds to one syllable makes characters play an important role in symbol-sound correspondences. Basically, in the Chinese writing system a symbol (character) corresponds to a spoken syllable, first. The sound of the syllable is the sound of the written character. Garman (1990) concludes that in Chinese the phonological aspects tend to be related to whole "word-forms", i.e. characters, rather than to segments, and that individual component strokes of the written characters do not themselves represent aspects of the phonological pattern.

Therefore, because of the lack of a grapheme-phoneme correspondence characteristic found in their first language, it seems difficult for Chinese students to learn that there are stable relationships found between letters and sounds in the English writing system. Many Chinese students tend to transfer their familiar character-learning strategies to learning English, an alphabetic language in which each letter or combination of letters represents a phoneme. Hence, they need to be explicitly taught to take advantage of lettersound correspondence strategies for learning an alphabetic language such as English (Huang, 1992). 


\section{GRAPHEME-PHONEME CORRESPONDENCES IN ENGLISH ORTHOGRAPHY}

In an alphabetic system like that of English, graphophonic values and compositionality are not the whole story. English orthography has been considered a highly inefficient system that fails to represent in consistent fashion the relationship between graphic symbols and phonetic expression. The phonemic principle of "one symbol for each distinctive sound-segment" is apparently violated (Venezky, 1970). Furthermore, the many changes that have occurred in the sound system of the words have not always been reflected in changes in the spelling of the words that were affected (Fromkin \& Rodman, 1988)

The irregularities between graphemes (letters) and phonemes (sounds) are demonstrated by Fromkin and Rodman (1988) as follows: different spellings for the same sound, the same spellings for different sounds, "silent letters," and "missing letters." (p. 356).

\begin{tabular}{|c|c|c|c|c|}
\hline $\begin{array}{l}\text { Same Sound, } \\
\text { Different } \\
\text { Spelling }\end{array}$ & $\begin{array}{l}\text { Different } \\
\text { Same } \\
\text { Spelling }\end{array}$ & & $\begin{array}{l}\text { Silent } \\
\text { Letters }\end{array}$ & $\begin{array}{l}\text { Missing } \\
\text { Letters }\end{array}$ \\
\hline $\begin{array}{l}\text { /aI/ } \\
\text { aye } \\
\text { buy } \\
\text { by } \\
\text { die } \\
\text { hi } \\
\text { Thai } \\
\text { height } \\
\text { guide }\end{array}$ & $\begin{array}{l}\text { thought } \\
\text { though } \\
\text { Thomas } \\
\text { ate } \\
\text { at } \\
\text { father } \\
\text { many }\end{array}$ & $\begin{array}{l}|e| \\
|æ| \\
|a| \\
|\varepsilon|\end{array}$ & $\begin{array}{l}\text { listen } \\
\text { debt } \\
\text { gnosis } \\
\text { know } \\
\text { psychology } \\
\text { right } \\
\text { balm } \\
\text { honest } \\
\text { bomb } \\
\text { clue }\end{array}$ & $\begin{array}{l}\text { use /juz/ } \\
\text { fuse /fjuz/ }\end{array}$ \\
\hline
\end{tabular}

Nevertheless, Wolfram and Johnson (1982) have claimed, "Although the system certainly reveals complexities in its organization, English is hardly the haphazard, illconceived system that it has been made out to be" (p. 198). Several researchers argue that a logical system of impressive regularity in English orthography emerges on a more 
“abstract" level (Chomsky \& Halle, 1968; Venezky, 1967, 1970). It has been asserted that the letter-sound relationships in English are regular in the sense that they are predictable, but the phonological values of the symbols change as result of graphic, phonological, or grammatical conditioning.

The spelling system of the English language is based on the alphabetic principle. Written words are composed of sequences of letters that roughly correspond to the phonemes of spoken words. (Griffith \& Olson, 1992). However, modern English orthography fails to represent in consistent fashion the relationship between graphic symbols and phonetic expression. First, the phonemic principle of "one symbol for each distinctive sound-segment" is apparently violated in English orthography (Venezky, 1970). Second, the orthography does not always represent what we know about the phonology of the language. The many changes that have occurred in the sound system of English have not always been reflected in changes in the spelling of the words that were affected (Fromkin \& Rodman, 1988).

Concerning the violation of the phonemic principle, more than 40 phonemes are identified for English. Given the 26 letters of the alphabet available for use in the English writing system, it seems obvious that orthographic representation must go considerably beyond the simple correspondence of one letter for each significant phonological unit. A single letter for each significant phonological unit is not sufficient, so the system utilizes the available symbols in some rather ingenious ways. First, there are a number of digraphs (pairs of letters representing a single sound unit), such as $t h, c h, s h$ or $o o$ which are just as basic to the English orthographic symbols as $a$ and $b$. Second, the well-known use of a vowel + consonant $+\mathrm{e}$ indicates a pattern different from a vowel + consonant, as in mate and fate compared with mat and fat. Third, letters may even show patterns of alternation based solely on their distribution within words. For example, $y$ is replaced by $i$ when certain kinds of suffixes are added to the form, as in mercy/merciful and icy/iciest (Wolfram \& Johnson, 1982).

In a major spelling research project conducted at Stanford University (Hanna, 1966), the researchers examined the consistency of grapheme-phoneme relationships in 
17,000 words, and analyzed the various structures of American English orthography with a computer. By considering (1) phonological factors (position, stress, and surrounding environment of letters); (2) morphological factors (compounding affixation, and word families); and (3) syntactic/semantic factors (knowledge about morpheme boundaries) the researchers were able to devise an algorithm (a set of rules) that resulted in very accurate spelling (Hanna, 1966).

Moreover, in fact, there are far fewer cases of symbol-sound irregularity in English than are usually attributed to the system. But there are some. The correspondence of $o$ to $/ I /$ in women is an uncommon and unpredictable correspondence for $o$. The correspondence of $e a$ to /i/ in bead and teach, and to / $/$ in dead and treachery, is irregular, since there is no consistent basis for predicting different phonological correspondences for the symbol. The case of $o$ corresponding to /I/ is really an "exception," whereas $e a$ for $/ i /$ and $/ \varepsilon /$ is the pattern for a relatively large subgroup of words. The latter represents a difference between what Venezky (1967) labels as "major" (ea for /i/) and "minor" ( $e a$ for $/ \varepsilon /$ ) correspondence patterns (p. 85-86). Such a distinction in kinds of irregularity seems useful in terms of systematically teaching the letter-sound correspondences of English. Minor correspondences may be taught as sets of items, whereas exceptions are most effectively treated as true exceptions in terms of learning (Wolfram \& Johnson, 1982).

The grapheme-phoneme relationships in English are regular in the sense that they are largely predictable. Regularity refers to any case that can generally be predicted on a non arbitrary basis by a learner of the system. This means that cues from the system can be used to predict the correspondence, without appealing to rote memorization of particular items (Wolfram \& Johnson, 1982). Garman (1990) indicates that although the English alphabet may be seen as violating a very simple spelling-to-sound correspondence, it actually embodies a set of relationships that are considerably more sophisticated, and carry a number of advantages. Since the regularities existing in the English writing system are not simple but sophisticated, the spelling principle will not be easily acquired even for native speakers, not to mention its second language learners. Therefore, it is reasonable to 
assume that EFL students such as Chinese, whose first language is logographic, will need explicit instruction concerning graphophonic correspondences in English orthography.

\section{WHY CHINESE STUDENTS SHOULD BE TAUGHT ENGLISH GRAPHOPHONIC CORRESPONDENCES}

\section{English Graphophonic Correspondences Can Help Chinese Students in Vocabulary Learning}

Vocabulary is usually introduced in the context of reading material in ESL and EFL classes. It seems that many teachers assume that by providing a definition, examples, and pronunciation of a word to students, the students can learn that word easily by themselves in its reading context. This assumption neglects the fact that students need a fundamental ability - that is, decoding words - to start to learn their second language. Although decoding words is not sufficient, by itself, to learn the language, it is a basic ability to start with. Teachers cannot simply assume that students themselves can figure out the relationship between the spelling and sounds since the English orthography seems so highly irregular and inconsistent at the surface level-the one-to-one correspondence level. To process English vocabulary, Huang (1992) concludes that Chinese students need to be trained to become independent learners by developing graphophonic strategies.

Many Chinese students cannot pronounce a new English word without the teacher first reading the word to them even if they have studied the language five or six years. In Taiwan, many English teachers also assume that students can figure out the relationships between letters and sounds in English, and do not pay attention to giving them any explicit instruction to help students gain the knowledge. The students who do not know English graphophonic correspondences are deprived of any phonological access to new words and would have difficulty in processing new English words, as well as building a lexicon to use in listening, speaking, reading, and writing. 
English Graphophonic Correspondences Can Help Chinese Students Pay Attention to Pronunciation

Students in Taiwan learn English as a required subject beginning in junior high school. They will be given training in letter names and sounds at the very beginning of study. Beginning language learners usually start by learning new words written in a new writing system. Normal English course in Taiwan emphasizes reading and grammar. Chinese students of English usually encounter vocabulary items in print, so their vocabulary learning is consequently through the visual mode instead of the auditory mode. Four steps are usually used to memorize an English word: (1) looking at the target word, (2) pronouncing it (if given the pronunciation of the word), (3) reading its Chinese translation, and (4) spelling the word orally while simultaneously writing down the spelling (Huang, 1992). In the first three steps, students try to associate the shape of the word with its sound and meaning; in the fourth step, students memorize a word letter by letter just as they memorize a character stroke by stroke.

Since there are no grapheme-phoneme correspondence rules in the Chinese writing system and the radical-sound correspondences in Chinese are highly flexible, Chinese students learning English do not usually take advantage of the graphophonic correspondence generalizations in a target language, such as English. They frequently omit the second step (pronouncing the word) and try to memorize written words without knowing their sound. It is no wonder that Chinese students in Taiwan have a difficult time learning English words if they simply try to memorize words letter-by-letter without knowing the letter-sound correspondences. Thus, Chinese students need to be taught to master graphophonic correspondences in English, so they can sound out new words, practice the pronunciation of familiar words, and recall the words they have placed in their mental lexicon. 
The Connections between Spelling and Meaning in English Orthography Can Help

\section{Chinese Students Develop Word Knowledge}

Although English orthography does manifest a fair number of inconsistencies in strict one-to-one letter-sound correspondences, it optimally does reflect the semantic relationships among words. Chomsky and Halle (1968) have claimed that the correspondence of spelling to meaning is often direct in the English writing system. Spelling also corresponds to sound, but this correspondence is "indirect". Although this claim may be exaggerated, it is true to a certain extent. There are many English words that are related in meaning and related in spelling. Although the sound may change, the spelling changes little as in the following word pairs: please/pleasant, impose/imposition, remedy/remedial. When spelling does change in related words, it usually follows predictable structural patterns: explain/explanation, retain/retention.

Similarly, Venezky (1970) also has asserted that for English orthography, the phonemic (sound) and the morphemic (meaning) tendencies are equally strong. In addition, morphemic identity is seldom preserved at the expense of the more general phonemic patterns. Also, the general phonemic patterns, from all appearances, tend to preserve morphemic identity. Thus, in

$$
\begin{aligned}
& \text { opaque - opacity } \\
& \text { electric - electricity } \\
& \text { plastic - plasticity }
\end{aligned}
$$

-qu- in opaque changes to -c- in opacity; the morphemic identity is not preserved.

However, it does not operate at the expense of, but rather encourages the implementation to, the more general phonemic patterns $-\mathrm{c}-=/ \mathrm{s} /$ (when $c$ is followed by $i$ ) in word pairs such as electric/electricity, plastic/plasticity, etc.

Recognizing the connections between English spelling and meaning is more dependent on visual identification and similar to the character-learning mode of Chinese students. Thus, the spelling/meaning connection should be more easily accepted by Chinese students than other techniques. It still needs to be pointed out for them, however. Templeton (1983) has noted that knowledge of the spelling/meaning connections in words 
and of the sequence in which they can be studied can provide the foundation for expanding and elaborating students' vocabulary. Moreover, the subtle relationships between spelling, meaning and sound in those patterns may need to be pointed out for students, too.

Templeton (1983) has also stressed that students need to become conscious of the general patterns that underlie words, and to realize that to learn a word does not mean one learns a single, discrete item. Rather, they can be taught to subdivide and perhaps expand an existing meaning category that is represented by other words that are already known. Students need to realize, moreover, that many of these words may be similar in form to the new word. It is in this latter regard that the spelling system, by visually expressing the commonalties among related words, provides the raw data for "analogical formation" of meaning relationships in language as well as higher-order phonological rules.

\section{HOW TO TEACH ENGLISH GRAPHEME-PHONEME CORRESPONDENCES}

The concern here should be the question of which level of linguistic awareness is required for learning the English writing system and which level of linguistic awareness is more compatible with the cognitive development of readers.

\section{Phonemic Awareness}

Many researchers have done studies which suggest that phonemic awareness is strongly related to success in beginning to read alphabetical languages (e.g., Bialystok, 1991; Byrne \& Fielding-Barnsley, 1989; Cunningham, 1990; Griffith \& Olson, 1992; Yopp, 1992). Griffith and Olson (1992) suggest several ways for teachers to help learners develop phonemic awareness. To make the instruction more explicit, Cunningham (1990) has claimed that providing learners with a metalevel framework of how language can be examined independently of meaning, how segmentation and blending are involved in recoding, of why it is helpful to employ these skills along with the knowledge of when segmentation and blending of phonemes should be utilized, may be useful. Although phonemic awareness is not sufficient for reading the language, it is helpful if learners can 
come to understand the basic nature of alphabetic orthography. Teaching phonemic organization and grapheme-phoneme associations can act complementarily to promote acquisition of alphabetic insight (Byrne \& Fielding-Barnsley, 1989).

\section{Patterns from Symbols to Sounds}

Wolfram and Johnson (1982) have concluded that in English orthography there are more predictable patterns in going from symbols to sounds (decoding) than from sounds to symbols (encoding). Besides, Chinese students do not need or cannot use an "encoding" skill (from sounds to symbols) in learning English since they learn English usually from written forms. For this reason, there is no sound association which has been stored in their mind. Therefore, what I will teach students will focus on generalizations from symbols to sounds. A series of sound patterns of consonants and vowels will be cited from Heilman (1993), Cummings (1988), Prator (1985) and Rinsky and Griffith (1978).

\section{Relationships among Spelling, Meaning and Sound}

Venezky (1967) has argued that present English orthography is not merely a letterto-sound system riddled with imperfections, but, instead, a more complex and more regular relationship wherein spelling units are not related directly to sound, but to an intermediate (morphophonemic) level first, and then to sound. Venezky (1970) also has asserted that for English orthography, the phonemic (sound) and the morphemic (meaning) tendencies are equally strong. Hence, students may be led to identify the parts of a word which form meaning units or pronunciation units within the word on a morphophonemic level. Throughout a process of exploring meaning units and pronunciation units, students are provided with opportunities for building on vocabulary and the knowledge of the relationships between spelling, meaning and sound. The patterns I choose for the instruction are cited from Shane Templeton's research (1983, p 9-14). Those patterns will show students the relationships between spelling, meaning and sound within word pairs or word families on a morphophonemic level. 


\section{CONCLUSION}

In Taiwan, many teachers assume that by providing the definition, examples, and pronunciation of a word to students, the students can learn that word easily by themselves just through reading. This assumption neglects the fact that students need the fundamental ability of processing words to begin to learn their second language. Although processing words is not sufficient for learning the language, it is a basic ability with which to begin. It seems necessary to reconsider the assumption that students can figure out the relationships between letters and sounds by themselves, i.e., that they can recode words without any training. Without explicit instruction of graphophonic correspondences in English orthography, Chinese students tend to transfer their familiar ways of learning characters to their English word-learning process. Teachers cannot simply assume that students, by themselves, can figure out the relationship between spelling and sounds, since English orthography seems so highly irregular and inconsistent at the surface level, the one-to-one correspondence level.

On the basis of my review of past research, the following notion seems convincing: graphophonic knowledge is helpful for Chinese students to learn English words. Without instruction of English graphophonic correspondences, Chinese students tend to transfer their familiar ways of learning Chinese characters to learning English words. There are three main reasons why Chinese students should be taught English graphophonic correspondences. First, English graphophonic correspondences can help Chinese students in vocabulary learning. Second, English graphophonic correspondences can help Chinese students pay attention to pronunciation. Third, the connections between spelling and meaning in English orthography can help Chinese students develop word knowledge.

To give students the knowledge, the explicit instruction in my study will include segmenting and representing the sounds heard in English words as well as how to organize those phonemes and how to associate graphemes with phonemes. In increasing their vocabularies, students can be trained to become independent learners by applying graphophonic knowledge. In addition, a series of spelling patterns of vowels and 
consonants, going from symbols to sounds, is included in the instruction. By considering phonological and morphological factors, an algorithm (a set of rules) that results in accurate spelling can be devised. Furthermore, I have included instruction in the spelling/meaning connections within English words to provide students a foundation for expanding and elaborating their vocabulary. I have also shown students the subtle relationships among spelling, meaning, and sound in English orthography on a morphophonemic level. 


\section{CHAPTER III}

\section{METHOD}

This study examines whether or not Chinese learners of English can benefit from instruction in English grapheme-phoneme correspondences while learning English vocabulary; this has been discussed in Chapter II. If any strong relationship can be found, the results may contribute to the development of a new vocabulary teaching method for students of logographic languages, or even for other ESL/EFL learners.

\section{GENERAL DESIGN OF THE STUDY}

The general design of my study is based on the research of Huang (1992), and Baron and Treiman (1980). Baron and Treiman assert that the ability to pronounce regular non-words is an indication of children's ability to use graphophonic rules in reading. In Huang's study, she modified the design of Baron and Treiman's research by using real words in her research. Students were given a vocabulary learning session in which students learned assigned, unknown English words in a traditional way, by providing a definition in Chinese, and an example sentence. Huang assumed that each subject's degree of graphophonic knowledge could be measured through the accuracy and speed of his or her pronunciation performance on oral reading. After the vocabulary learning session, students were required to recall the words which they had just learned and to read these words orally. According to Huang, if the graphophonic strategy can help Chinese students in learning new words more effectively, there should be a significant positive correlation between the number of words pronounced correctly and the vocabulary test scores.

I adapted the design of Baron and Treiman (1980) to give students a non-word "pre-test" in my study. Subjects were asked to pronounce 10 regular non-words, such as 
"fash" and "lome" etc. The non-words I were inspired by the "stimuli" used in the word reading test in Baron and Treiman's research. These non-words were also checked by several native English speakers to see if they involve the most general graphophonic rules. These 10 non-words will be included in Appendix A. The purpose of this non-word test was to investigate whether or not the subjects already had knowledge of graphophonic correspondences before treatment.

In contrast to Huang's design, I actually taught English grapheme-phoneme correspondences to Chinese students and investigated whether or not the instruction would help them recall more English words. In the school where I conducted this project, I was introduced as a guest speaker to two classes who were the subjects in the research. During the treatment, both classes took the normal English course two hours a week from the same English teacher assigned by the school. In addition, both classes also had special instruction for six weeks, two hours a week, from the researcher. The difference between these two groups during this special instruction was as follows: The control group was given only instruction in pronunciation while the experimental group was given instruction both in pronunciation and graphophonic correspondences.

After the special instruction, both groups were given a vocabulary learning session to learn 30 words which they had not been taught, chosen from the vocabulary list in their textbook. In this vocabulary learning session, the students were taught in this way: They were given a definition in its Chinese, IPA (International Phonetic Alphabet) version and also an example sentence for each word. I wanted to know whether or not instruction of graphophonic correspondences would help the experimental group recall more English words.

To examine and compare the two groups, both groups were tested on their vocabulary recall achievement based on the vocabulary recall test used in Huang's research. They had a short-term vocabulary recall test right after the vocabulary learning session, and a long-term vocabulary recall test two weeks later. In each test, they were asked to recall the meanings of 10 words out of 30 words they had learned in the 
vocabulary learning session, but the words used in the short-term test and the long-term test were different.

As well as examining the students' vocabulary recall achievement, I was also interested in whether or not the instruction would affect students' performance in pronunciation. Therefore, after the short-term recall test, 15 students from each class were asked to pronounce the ten words which were the correct answers to the short-term recall test.

The vocabulary learning session, the short-term recall test, and the pronunciation test had to take place on the same day. Thus, due to the time limitation, all the students answered only 10 questions on the short-term recall test, after which only 15 students from each class had time to be recorded while they were pronouncing the ten words. There were also 10 questions on the long-term recall test because it is convenient for the same number of items to be analyzed by one statistical method.

\section{SUBJECTS}

Students who are in their second year of a junior college in Taiwan participated in this study. They have been learning English for more than four years. This research investigates if they performed better in vocabulary recall tests after being given instruction concerning the link between English letters and sounds. There were two groups: a control group and an experimental group. Each had about 50 students, consisting of males and females between 18-19 years old. There were two classes of students, one from day school and the other from night school, assigned by a junior college in Kaohsiung, Taiwan. I randomly chose one of the two classes to be the experimental group. All of the students were informed that they did not have to participate in this study. Although they had to attend every class according to the regulations of the school, they could choose not to take part in the research and evaluation. Therefore, only the data of students who volunteered to participate in the whole project are included in this study. 
All the voluntary subjects were given a non-word test before the treatment. In that non-word test, all of them were asked to pronounce 10 regular non-words. The number of regular non-words that students could pronounce correctly and quickly served as an indicator of the degree of graphophonic development that they had achieved. The data of students who could pronounce more than 7 of 10 regular non-words in the list were not included in this study, either.

All the students were told that both groups would take part in a research project on how Chinese students learn English vocabulary, without knowing there were differences in the instruction given to them. In addition, I informed them that there would be an "evaluation," but they were promised that any data from the evaluation would not affect their grade for the English class. Because these two groups were from day and night school respectively, they were unlikely to share knowledge from the instruction.

\section{VARIABLES}

There are two main identified variables in the hypotheses: The students' vocabulary recall achievement is the dependent variable, and the method used to teach English grapheme-phoneme correspondences is the independent variable. This research attempts to find out if the independent variable will affect the dependent variable at a statistically significant level. Because each single group of students was tested more than once-on a non-word test, as well as on short-term and long-term vocabulary recall tests, the investigation is a repeated-measures study. To analyze the results of these tests, a repeated-measures ANOVA (analysis of variance) will be used.

I am also interested in whether or not the instruction affected students' performance in pronunciation. Right after the short-term vocabulary recall test, 15 students from each class were asked to pronounce the ten words which are the correct answers on the test. I wanted to know if there is a correlation coefficient between two variables-students' achievement of vocabulary recall and their performance in pronunciation, which is not, however, included as a dependent variable investigated in the 
hypotheses. The Pearson product-moment correlation coefficient will be used in this analysis.

\section{INSTRUMENTS AND MATERIALS}

In the "pre-test" before the treatment, the 10 regular non-words (see Appendix A) used are inspired from the research of Baron and Treiman (1980). These words are called regular non-words because they have no lexical entries, hence cannot be accessed lexically; but can be responded to via grapheme-phoneme conversion. A pronunciation response to regular non-words is assumed to be mediated via grapheme-phoneme correspondence route (Garman, 1990). These regular non-words involve the most general grapheme-phoneme rules. The number of words out of the 10 words that students could pronounce correctly and quickly will serve as an indication of the degree of graphophonic development they had achieved before the treatment.

During the special instruction, both groups were taught all the phonemes in English and were given a great deal of practice in some vowels and consonants which students have problems pronouncing correctly. Since the course time was administered equally for both groups, the control group had more practice in pronouncing words from the reading material used for the normal English course. The experimental group had instruction in English graphophonic correspondences, but with less pronunciation practice than the control group. The experimental group still performed better on the pronunciation test (see page 41). Therefore, the amount of pronunciation practice does not seem to be an important uncontrolled variable.

In the lessons on English graphophonic correspondences, first of all, the experimental group was provided with explicit teaching in sound segmentation and in letters representing the sounds in words. They were taught a series of stable patterns for predicting the pronunciation of consonants and vowels. The patterns I chose were the decoding code, the link going from symbols to sounds, since it is more predictable than the link going from sounds to symbols. In other words, I taught students how to organize 
those phonemes and how to associate graphemes with phonemes. In increasing their vocabularies, students can be trained to become independent learners by applying graphophonic knowledge. Students were trained to be aware that English graphophonic correspondences are regular in the sense that they are largely predictable.

Furthermore, the experimental group was shown the connections among spelling and meaning in English orthography. Instruction of the spelling/meaning connections in words should provide the foundation for expanding and elaborating students' vocabulary. Besides, the subtle relationships between spelling, meaning, and sound in those patterns were pointed out to the students. That is, I showed students the relationships between spelling, meaning and sound within word pairs or word families on a morphophonemic level. The control group only practiced pronouncing the words without being informed of any connections between spelling and meaning. All curricula for the control group and the experimental group are included in Appendix B and Appendix $\mathrm{C}$ respectively. This special instruction took six weeks.

In the seventh week, both groups were given a vocabulary learning session to learn 30 words which they had not been taught in their class. Those words were chosen from the vocabulary list in the following lessons in their textbook which were not supposed to be already learned by the students. In this vocabulary learning session, the students were taught in a traditional way, through being given a definition in its Chinese, IPA (International Phonetic Alphabet) version, and also an example sentence for each word. These 30 English words, their Chinese definitions and example sentences will be shown in Appendix D.

After the vocabulary learning session, two sets of tests, following the format of multiple-choice standardized vocabulary tests used in Taiwan, served as test material for the short-term and the long-term vocabulary recall tests. For example,

( ) $1 . \mathrm{A}(\mathrm{n})$
(a) journal
(b) research
(c) length
(d) location is a magazine that is published regularly. 
Each test had 10 questions resembling the above example. To finish the sentence, students needed to choose the right word to fill in the blank. Thus, they had to recall the meanings of the words and then make the choice. Both tests are shown in Appendix E.

\section{SUMMARY}

This research examines whether or not explicit instruction in English graphophonic correspondences will influence students' achievement on short-term and long-term vocabulary recall tests. The hypotheses and the results in this research cannot be claimed as a cause-effect relationship. It will not be certain that the instruction of graphophonic correspondences is the only factor that affects students' performance. However, if the hypotheses are supported by the results at a statistically significant level, it will lend support to the claim that the instruction has a positive influence on Chinese students' vocabulary recall achievement, suggesting that an English teacher should teach English graphophonic correspondences to Chinese students. 


\section{CHAPTER IV}

\section{RESULTS}

In this chapter the results of the various measures used during the research are reported: an English vocabulary test that both groups took the previous semester, a nonword test before the treatment, a short-term vocabulary recall test and a pronunciation test right after the vocabulary learning session, and a long-term vocabulary recall test two weeks later. To test the equality of the two groups before the treatment, the vocabulary test before the experiment and the non-word test are analyzed by a $t$-test method. In addition, results from the non-word test, short-term and long-term recall tests are analyzed by a repeated-measures ANOVA (analysis of variance). Furthermore, the Pearson product-moment correlation coefficient is used to analyze whether or not there is a strong relationship between the students' performance on the short-term vocabulary recall test and the pronunciation test.

\section{HYPOTHESES}

The research has been designed to compare two groups under different treatments-instruction in pronunciation only versus instruction in pronunciation and grapheme-phoneme correspondences. The research hypotheses have been made as follows:

1. Chinese students who have been given lessons in both pronunciation and grapheme-phoneme correspondences will recall more English words on a short-term vocabulary test immediately after a vocabulary learning session than will the students who have been given only the lessons in pronunciation. 
2. Chinese students who have been given lessons in both pronunciation and grapheme-phoneme correspondences will also recall more English words on a long-term vocabulary test two weeks after a vocabulary learning session than will the students who have been given only the lessons in pronunciation.

Two groups of second-year junior college students in Taiwan participated in this study. Before the treatment, I asked all students to pronounce 10 regular non-words. Those students who could pronounce more than 7 words were considered to be too good to be included in this experiment. In the treatment, students in the control group received instruction in pronunciation only, while students in the experimental group received instruction in both pronunciation and grapheme-phoneme correspondences. The treatment took six weeks. In the seventh week, students were given a vocabulary learning session to learn 30 words which they had not been taught before. To investigate these two hypotheses, two vocabulary recall tests were given to the two groups. These two tests were based on the tests used in the research of Huang (1992), and modified by the researcher for this study. One short-term vocabulary recall test was given immediately after the vocabulary learning session and one long-term vocabulary recall test two weeks later. Right after taking the short-term recall test, 15 students from each class were asked to pronounce 10 words which were the answers to the short-term recall test. I wanted to see if there was a correlation between students' performance in pronunciation and achievement of vocabulary recall.

\section{BEFORE THE TREATMENT}

Before the experiment, I wanted to know if the two groups were on a similar level of English vocabulary ability. The vocabulary scores of the final English exam that both groups took the previous semester were analyzed according to a t-test. That test was multiple-choice format and consisted of 10 questions. The analysis shows us there was no statistically significant difference between the average scores of the 38 students in the 
control group and the 39 students in the experimental group on this English vocabulary test. As observed in the $t$-test for equality of means, since the significance level $(p=.149)$ is too large to reject the equality hypothesis, the two population means may be equal. The control group and the experimental group did not perform differently on the English vocabulary test before the experiment, at least not at a significant level; therefore, it might be assumed that the two groups had a similar level of vocabulary ability before the experiment. Table I illustrates the analysis of the data from the English vocabulary test before the experiment.

TABLE I

t-test for the English Vocabulary Test before the Experiment

\begin{tabular}{lcccc}
\hline Variable & Cases & Mean & Standard Deviation & SE of Mean \\
\hline Before the Experiment & & & & \\
Control Group & 38 & 7.1526 & .6534 & .106 \\
Experimental Group & 39 & 7.4205 & .9367 & .150 \\
\hline
\end{tabular}

Mean Difference $=-.2678(p=.149>.05)$

Before the treatment, all the students were asked to pronounce 10 regular nonwords which involve the most general grapheme-phoneme rules, such as "fash" and "lome". The data of students who could pronounce more than 7 of the 10 regular nonwords in the list were not included in this study; those students were assumed to have enough knowledge of English grapheme-phoneme correspondences already. Originally, there were 49 students in the control group and 52 students in the experimental group. After excluding those students with enough prior knowledge, there were 38 students in the control group and 39 students in the experimental group. These students were assumed to have less than adequate knowledge of English grapheme-phoneme correspondences.

After analysis of the means of the two groups on the non-word test, the average scores of the two groups turned out not to have a statistically significant difference. 
Therefore, it was indicated that the prior knowledge of the 38 students in the control group and the 39 students in the experimental was almost equivalent before treatment. In this analysis, the significance level, .310 , was too large to reject the equality hypothesis; the difference between two population mean scores did not seem statistically significant. Table II shows the analysis of the two groups on the non-word test.

\section{TABLE II}

t-test for the Non-word Test before the Treatment

\begin{tabular}{|c|c|c|c|c|}
\hline Variable & Cases & Mean & Standard Deviation & SE of Mean \\
\hline \multicolumn{5}{|l|}{ Non-word Test } \\
\hline Control Group & 38 & 4.1316 & 1.417 & .230 \\
\hline Experimental Group & 39 & 4.4359 & 1.188 & .190 \\
\hline
\end{tabular}

Mean Difference $=-.3043(p=.310>.05)$

The above two analyses seem to support the equality of the two groups before the treatment. First, with similar performances on the vocabulary test the previous semester, they were supposed to be on a similar level of vocabulary ability. And according to the second analysis, the 38 students in the control group and 39 students in the experimental students were considered to have almost equal graphophonic knowledge before the treatment.

\section{AFTER THE TREATMENT}

In the treatment, both groups were given "special" instruction by the same instructor, the researcher. Students in the control group received instruction in pronunciation only, while students in the experimental group received instruction in both pronunciation and grapheme-phoneme correspondences. The treatment took six weeks. In the seventh week, students were given a vocabulary learning session to learn 30 words 
that they had not been taught before. Those 30 words were chosen from their text book. To investigate the two hypotheses in this study, two vocabulary recall tests were given to two groups under the different educational instructions. These two tests were based on the tests used in the research of Huang (1992), and modified by the researcher for this study. One short-term vocabulary recall test was given immediately after the learning session and one long-term vocabulary recall test two weeks later. In each test, students had to recall 10 words out of the 30 words that they just learned in the vocabulary learning session. Since the interval between the two tests was only two weeks, the words used in the shortterm and long-term tests were different to prevent students from retaining memory from one test to the other.

\section{Statistical Method}

In this experiment the same subjects under different treatments were tested repeatedly on the non-word test, the short-term and long-term recall tests. Therefore, a repeated-measures analysis of variance (ANOVA) with 3 repeated measures across time and 1 between-subjects factor (different treatment) is used to compare the results. In essence, the method employed in the analysis of variance is to compute the variances of the separate groups being tested for mean differences. The scores of all subjects in the subgroups are then artificially combined into one pooled group. If the variance of the combined group is approximately the same as the average variance of the separate subgroups, then there exists no significant difference between the means of the separate groups. If, on the other hand, the variance of the combined total group is considerably larger than the average variance of the separate subgroups, then a significant mean difference exists between subgroups.

In this statistical technique, some statisticians refer to the between-groups variance as reflecting "systematic variability", whereas the within-groups variance reflects "error variability". The term "error" relates to the fact that the researcher has made no attempt to control for individual differences (variance) within each group, such as by adding other independent variables to the design. Because these extraneous (but not necessarily 
irrelevant) sources of variance are not controlled, they are labeled as the within-groups error variance, or unsystematic variance.

Thus the between-groups or systematic variance reflects the variability due to the independent variable-in this experiment, the differences among the two different methods of instruction. The unsystematic, within-groups, or error variance reflects the variability due to all the remaining uncontrolled factors. To the extent that the systematic variance is less than or equal to the unsystematic or error variance, the researcher would be hard put to claim any real differences due to treatment conditions. The ratio of the between-groups mean square to the within-groups mean square is exactly a reflection of this comparison.

\section{Average Scores}

The previous analysis showed no statistically significant difference between the average scores of the two groups on the non-word test. This would indicate that both groups had a similar amount of prior knowledge before treatment. On the other hand, there was a statistically significant difference between average scores of the two groups on the short-term vocabulary recall test after the treatment. The experimental group performed better than the control group at a significant level (mean difference $=1.7126$, $p<.05)$. After receiving different methods of instruction, students in the experimental group seemed to recall more words than students in the control group. Table III presents the analysis of the short-term vocabulary recall test.

TABLE III

t-test for the Short-Term Vocabulary Recall Test

\begin{tabular}{lcccc} 
Variable & Cases & Mean & Standard Deviation & SE of Mean \\
\hline Short-Term Test & & & & \\
Control Group & 38 & 7.2105 & 2.094 & .340 \\
Experimental Group & 39 & 8.9231 & 1.306 & .209 \\
\hline
\end{tabular}

Mean Difference $=-1.7126(p<.05)$ 
Two weeks later, on the long-term recall test, there was also a statistically significant difference between average scores of the two groups $(p<.05)$. Moreover, the experimental group's vocabulary recall was much better than the control group (mean difference $=3.2476$ ). Table IV presents the analysis of the long-term vocabulary recall test.

TABLE IV

t-test for the Long-Term Vocabulary Recall Test

\begin{tabular}{lcrrrr}
\hline Variable & Cases & Mean & Standard Deviation & SE of Mean \\
\hline Long-Term Test & & & & \\
Control Group & 38 & 6.3421 & 2.017 & .327 \\
Experimental Group & 39 & 9.5897 & .637 & .102 \\
\hline
\end{tabular}

Mean Difference $=-3.2476(p<.05)$

\section{Interaction}

The mean difference between the two groups on the long-term test is bigger than on the short-term test. This may indicate that the different methods of instruction continued to affect the student's performance even two weeks after the treatment. To better illustrate the interaction between the two groups, the tendency of the average scores of the two groups will be discussed. The difference between the tests across time is analyzed by the ANOVA.

First, it is noticed that the average scores of both groups went up from the nonword test to the short-term test: The control group progressed 3.0789 on average, and the experimental group progressed 4.4872 on average. Table $\mathrm{V}$ summarizes the mean difference of average scores between the non-word test and the short-term test. 


\section{TABLE V}

Summaries of the Difference between

the Non-word Test and the Short-Term Test

\begin{tabular}{llcl}
\hline Variable & Mean & Standard Deviation & Cases \\
\hline For Entire Population & 3.7922 & 2.2788 & 77 \\
Control Group & $\mathbf{3 . 0 7 8 9}$ & 2.6649 & 38 \\
Experimental Group & $\mathbf{4 . 4 8 7 2}$ & 1.5706 & 39 \\
\hline
\end{tabular}

According to the ANOVA analysis, the mean difference of average scores between the non-word test and the short term test was statistically significant between the two groups $(\mathrm{F} 1,75=8.0297, .0059)$. It is shown that the experimental group progressed more than the control group at a significant level. Table VI illustrates the analysis of mean difference of average scores across time between the non-word test and the short-term test.

\section{TABLE VI}

Analysis of Variance of the Difference across Time between the Non-word Test and the Short-Term Test

\begin{tabular}{|c|c|c|c|c|c|}
\hline Source of Variation & D.F. & Sum of Squares & Mean Squares & F Ratio & Sig of F \\
\hline Between Groups & 1 & 38.1686 & 38.1686 & 8.0297 & $.0059^{\star}$ \\
\hline Within Groups & 75 & 356.5067 & 4.7534 & & \\
\hline Total & 76 & 394.6753 & & & \\
\hline
\end{tabular}

Second, from the short-term test to the long-term test, it is shown that the experimental group's average score progressed .6667 on average, while the control group's average score regressed .8684 on average. In other words, the average scores of the control group went up from the non-word test to the short-term test, but went down from the short-term test to the long-term test. By contrast, the average scores of the experimental group went up from the non-word test to the short-term test, and again slightly up from the short-term test to the long-term test. It is indicated that the effect of the instruction in graphophonic correspondences seemed constant, while the effect of the 
instruction in pronunciation was not stable. Table VII summarizes the mean difference of average scores between the short-term test and the long-term test.

\section{TABLE VII}

Summaries of the Difference between

the Short-Term Test and the Long-Term Test

\begin{tabular}{|c|c|c|c|}
\hline Variable & Mean & Standard Deviation & Cases \\
\hline For Entire Population & -.0909 & 1.8295 & 77 \\
\hline Control Group & -.8684 & 2.0556 & 38 \\
\hline Experimental Group & .6667 & 1.1773 & 39 \\
\hline
\end{tabular}

From the previous discussion, obviously, the mean difference of average scores between the short-term test and the long-term test were statistically significant between the two groups ( $F 1,75=16.2750, .0001)$. Table VIII shows the analysis of mean difference of average scores across time between the short-term test and the long-term test.

\section{TABLE VIII}

Analysis of Variance of the Difference across Time between the Short-Term Test and the Long-Term Test

\begin{tabular}{|c|c|c|c|c|c|}
\hline Source of Variation & D.F. & Sum of Squares & Mean Squares & F Ratio & Sig of $F$ \\
\hline Between Groups & 1 & 45.3549 & 45.3549 & 16.2750 & $.0001 *$ \\
\hline Within Groups & 75 & 209.0088 & 2.7868 & & \\
\hline Total & 76 & 254.3636 & & & \\
\hline
\end{tabular}

Figure 2 on page 38 shows the average scores of the control and experimental groups on the non-word test, and the short-term and long-term vocabulary recall tests. Figure 3 on page 39 presents the Group $x$ Time interaction between the two groups, which were tested at different times. 
Figure 2. Average Scores of the Control and Experimental Groups

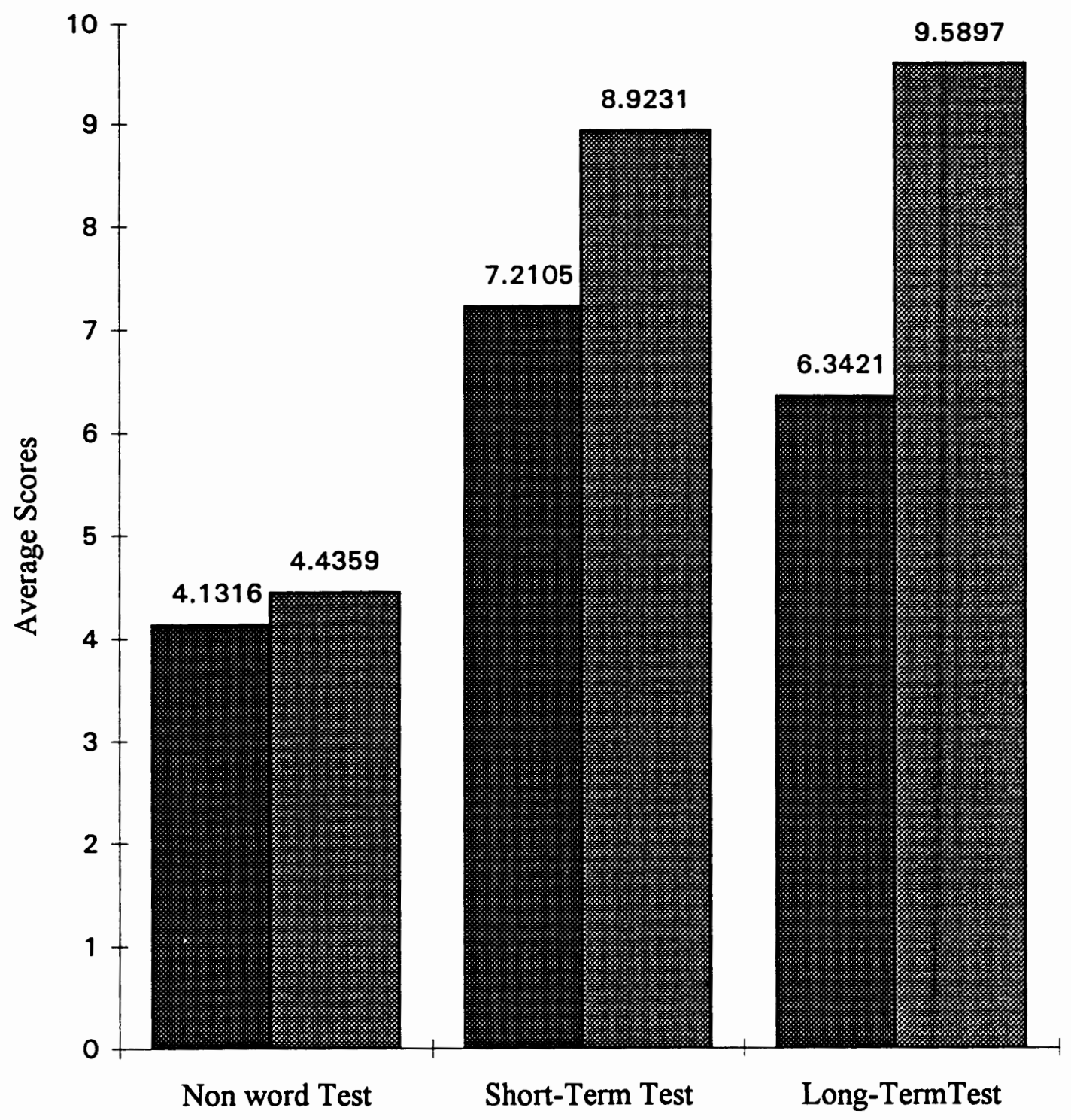


Figure 3. Group $x$ Time Interaction between the Control and Experimental Groups.

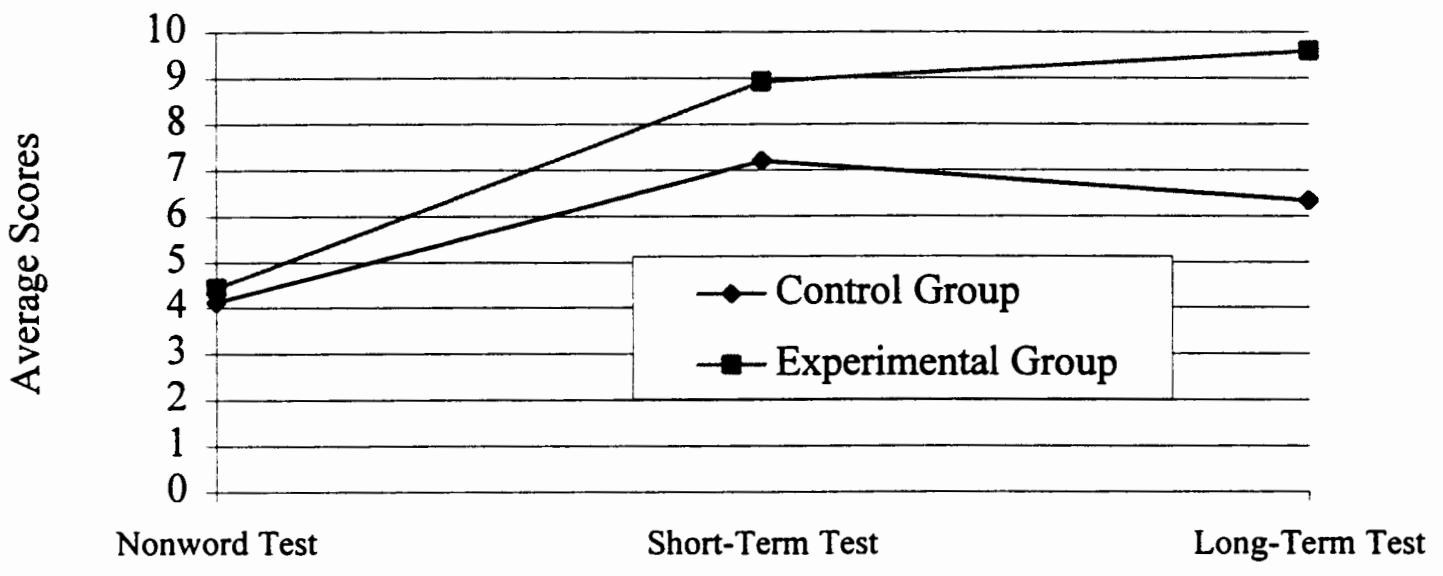




\section{CORRELATION}

As well as testing those two hypotheses, I was also interested in whether or not the instruction would affect students' performance in pronunciation, especially because of the difference of the time in pronunciation practice (see page 26). After the short-term vocabulary recall test, 15 students from each class were asked to pronounce the ten words which had been the correct answers to the short-term vocabulary recall test. These ten words are shown in Appendix F. Of those 30 students, 9 had not been part of this correlation analysis because they had pronounced more than 7 words correctly on the nonword test. Therefore, only 21 students' scores were counted-10 students in the control group and 11 students in the experimental group. I wanted to know if there was a correlation between these two variables-students' performance in pronunciation and their achievement of vocabulary recall. The most widely used measure of correlation, the Pearson product-moment correlation coefficient, is used in this analysis.

\section{Statistical Method}

The product-moment correlation coefficient is a statistic descriptive of the magnitude of the relation between two variables. Correlation coefficients are traditionally defined in such a way as to take values extending from -1 to +1 . A negative value indicates a negative relation: that is, $\mathrm{X}$ decreases as $\mathrm{Y}$ increases. A positive value indicates a positive relation where $\mathrm{X}$ increases as $\mathrm{Y}$ increases. The symbol $r$ is in common practice used to denote the sample value of the correlation coefficient. In general in interpreting the magnitude of the relation between two variables, $r^{2}$ is the coefficient of determination, regardless of directionality. The values of $r^{2} \times 100$ for values of $r$ from .10 to 1.00 is as follows:

\begin{tabular}{rrrr}
$r$ & $r^{2} \times 100$ & $r$ & $r^{2} \times 100$ \\
\hdashline .10 & 1 & .60 & 36 \\
.20 & 4 & .70 & 49 \\
.30 & 9 & .80 & 64 \\
.40 & 16 & .90 & 81 \\
.50 & 25 & 1.00 & 100 \\
\hline
\end{tabular}


According to analysis of the 21 students, there was a correlation coefficient between the students' performances on the pronunciation and vocabulary recall tests $(r=.674, p=.001)$. Therefore, almost 50 percent of the variance of one variable is predictable from the variance of the other. It is indicated that half of the scores of 21 students were correlated on the vocabulary recall test and the pronunciation test. Table IX presents the correlation coefficient between both tests that all 21 students took in the experiment.

TABLE IX

\begin{tabular}{|c|c|c|c|c|c|c|}
\hline Variable & No of Pairs & Corr & 2-tail Sig & Mean & SD & SE of Mean \\
\hline \multirow[t]{2}{*}{ Oral Test } & & & & 5.5238 & 2.040 & .445 \\
\hline & 21 & .674 & $.001^{*}$ & & & \\
\hline Short-Term Test & & & & 7.5714 & 2.135 & .466 \\
\hline
\end{tabular}

The relationship between the control and experimental groups became even clearer when each group was analyzed individually. There was a much higher correlation coefficient in the experimental group than in the control group $(r=.909, p=.000)$. With a correlation coefficient as high as .909 , the unexplained variance is very low. It appeared that almost every student who scored higher on the vocabulary recall test also performed better on the pronunciation test, even though they had less pronunciation practice than the control group (see page 26). Table $\mathrm{X}$ presents the relationship between the vocabulary recall and pronunciation tests that were taken by 11 students in the experimental group.

TABLE $X$

\begin{tabular}{|c|c|c|c|c|c|c|}
\hline Variable & No of Pairs & Corr & 2-tail Sig & Mean & SD & SE of Mean \\
\hline Oral Test & & & & 5.9091 & 2.343 & .707 \\
\hline & 11 & .909 & $.000^{*}$ & & & \\
\hline Short-Term Test & & & & 8.7273 & 1.489 & .449 \\
\hline
\end{tabular}


On the other hand, in the control group, there was no strong correlation between the vocabulary recall and oral tests, at least not at a statistically significant level $(\mathrm{r}=.542$, $p=.105$ ). The correlation of .542 means that there was nearly 75 percent unexplained variance. Table XI presents the relationship between the vocabulary recall and pronunciation tests that were taken by 10 students in the control group.

TABLE XI

\begin{tabular}{|c|c|c|c|c|c|c|}
\hline Variable & No of Pairs & Corr & 2-tail Sig & Mean & SD & SE of Mean \\
\hline \multirow[t]{2}{*}{ Oral Test } & & & & 5.1000 & 1.663 & .526 \\
\hline & 10 & .542 & .105 & & & \\
\hline Short-Term Test & & & & 6.3000 & 2.058 & .651 \\
\hline
\end{tabular}

In this experiment, a high correlation coefficient existed in the experimental group, while a low correlation coefficient existed in the control group. In psychology and education the presence of a correlation between two variables can rarely be interpreted as implying a direct causal relation. In many situations two variables are correlated, because both are correlated with an underlying variable or set of variables. Very simply $X$ and $Y$ may be correlated because both bear a direct causal relation to an underlying variable $\mathrm{Z}$. Therefore, it is assumed that the performance on the vocabulary recall and pronunciation tests may be correlated strongly or weakly probably because of the effect of the different treatments.

\section{SUMMARY}

In general, the students under different treatments performed differently at a statistically significant level. The experimental group recalled more words on both shortterm and long-term tests. Moreover, they behaved differently across time depending on which group they were in: The experimental group's performance continued to progress over time while the control group's performance fluctuated across time. There was also a correlation coefficient between the performance on the pronunciation and vocabulary 
recall tests for all 21 students; furthermore, this correlation coefficient was much higher in the experimental group than in the control group. Therefore, it seems reasonable to suspect that the performance on both tests was strongly correlated in the experimental group because of the instruction they had received in grapheme-phoneme correspondences. The data collected during the experiment support both hypotheses:

1. Chinese students who had been given lessons in both pronunciation and grapheme-phoneme correspondences performed better on the short-term vocabulary recall test immediately after the vocabulary learning session than did the students who had been given only the lessons in pronunciation.

2. Chinese students who had been given lessons in both pronunciation and grapheme-phoneme correspondences also performed better on the long-term vocabulary recall test two weeks after the vocabulary learning session than did the students who had been given only the lessons in pronunciation. 


\section{CHAPTER V}

\section{DISCUSSION OF RESULTS}

This chapter discusses the results of the study. General conclusions made from the findings are presented and their implications for teaching English as a second/foreign language to Chinese students are revealed. The limitations and methodological problems are also considered.

\section{DISCUSSION OF THE FINDINGS}

\section{Graphophonic Correspondences}

In learning English, the lack of knowledge of graphophonic correspondences is especially a problem for Chinese students, who are not familiar with alphabetic systems. The Chinese writing system is composed of characters. The sound (phoneme) corresponds to the whole word-form, i.e. the character, rather than to segments (strokes). The composition of strokes provide little or no hint about the pronunciation of the character. Thus for Chinese students, character learning means copying down each character stroke by stroke and identifying it by hints based on its shape. In contrast to alphabetic languages, pronouncing a Chinese character analytically through its component units (strokes) is impossible. Therefore, Chinese students generally do not analyze printed words phonetically when they begin to learn English. Instead, they tend to transfer their character-learning (logographic) strategy and learn English words through rote memorizing and visual identification. While this may be a good way to learn characters, it may not be the more efficient method for learning English words. Moreover, as the vocabulary grows and the number of visually similar words increases, the memory burden 
becomes severe and the logographic strategy becomes progressively more inaccurate in processing an alphabetic system, such as the English writing system.

In addition, a very curious phenomenon can be observed. That is, even after four or five years learning English, many Chinese students still cannot pronounce a new English word without the teacher first reading the word to them. Chinese students are very familiar with learning characters by rote, associating the visual shape of a word with its meaning. Thus even when they can get the IPA (International Phonetic Alphabet) form of an English word, many of them will associate the shape of the word with its IPA version without knowing the relationship between the letters and sounds. The students who do not know graphophonic correspondences must use other non-graphophonic strategies in learning English words. The questions then arise whether knowledge of graphophonic correspondences will help Chinese students learn English vocabulary more efficiently, or whether pronunciation practice is enough to facilitate Chinese students in learning English vocabulary.

\section{Hypotheses}

This study was done to investigate the relative effectiveness of experimental instruction of Chinese students. The research was designed to compare two groups under different treatments-instruction in pronunciation only versus instruction in pronunciation and grapheme-phoneme correspondences. The hypotheses were made as follows:

1. Chinese students who have been given lessons in both pronunciation and grapheme-phoneme correspondences will recall more English words on a short-term vocabulary test immediately after a vocabulary learning session than will the students who have been given only the lessons in pronunciation.

2. Chinese students who have been given lessons in both pronunciation and grapheme-phoneme correspondences will also recall more English words on a long-term vocabulary test two weeks after a vocabulary learning session than will the students who have been given only the lessons in pronunciation. 
In general, the students under different treatments performed differently at a statistically significant level. The experimental group did recall more vocabulary words on both shortterm and long-term tests. Furthermore, they behaved differently across time depending on which group they were in: The experimental group's performance continued to progress over time while the control group's performance fluctuated across time.

\section{Correlation}

The measures used to test the two hypotheses were written tests. Moreover, I was also interested in whether or not the instruction would affect students' performance on pronunciation. I wanted to know if there was a correlation between two variablesstudents' performance in pronunciation and their achievement of vocabulary recall. After the analysis of 21 students randomly selected from two groups, there existed a correlation coefficient between performance on the pronunciation test and the vocabulary recall test; furthermore, the correlation coefficient was much higher in the experimental group than the control group.

\section{Findings}

It appears that pronunciation instruction did not give Chinese students a significant advantage in recalling the words in written form. Making connections between graphemes (letters) and phonemes (sounds) seems to be more efficient in teaching written word recall. The better performance of the experimental group supports the hypotheses which were made. The control group's performance was not stable probably because there was no connection made between the words and pronunciation in the previous training and in this treatment.

The results do not really appear to support Channell's (1988) speculation that associations which are both semantic and phonological would be the most helpful in aiding the future recall of new vocabulary (see page 26 and 41). More pronunciation practice did not seem to give the control group an advantage. For Chinese students, perhaps knowledge of English grapheme-phoneme correspondences is more crucial. The 
knowledge is helpful probably because it is a supplement to their previous way of learning English vocabulary.

\section{CONCLUSION}

Although it is not known if the subjects who knew graphophonic correspondences were also superior in overall vocabulary skills and used every possible strategy in learning English words, it is certain that subjects who had not been taught graphophonic correspondences were more likely to learn less and recall less. The results at least suggest that the subjects who had graphophonic skills available were better learners than people who did not.

With the evidence from this study, it seems justified to assume that one learns new words better if he or she is aware of the correspondences between letters (graphemes) and sounds (phonemes). An explanation this study suggested is that the knowledge of graphophonic correspondences may tighten the association between graphemes and phonemes in the lexicon. A close association in the lexicon may facilitate both visual and phonological accesses to the presentations. Generally speaking, two accesses to a word in memory are superior to one. Instruction of grapheme-phoneme correspondences should be taught explicitly to Chinese students who seem to mainly depend on visual accesses to lexicon. A conscious and subconscious knowledge of these correspondences may help the students develop a strong sensitivity to such correspondences in both visual and phonological approaches to learning English words.

Another explanation suggested by these findings is that pronunciation instruction has limitations: Students have to follow the instructor whose accent might be American, British, or Australian. Students may be able to imitate their instructor's pronunciation in the class, but cannot be independent learners outside the class. Moreover, instruction in pronunciation only will not help students understand the spelling principle since the English orthography seems so highly irregular and inconsistent at the surface level. Instead, by developing graphophonic strategies, students can be trained to become more 
independent learners. They may speak English with their accent, but they have more control in learning an English word, knowing how graphemes match phonemes in that word. It may well be that independent learners are better learners.

\section{IMPLICATIONS FOR TEACHING ENGLISH TO CHINESE STUDENTS}

Currently, most vocabulary teaching in EFL courses in Taiwan is part of an intensive reading program, where the vocabulary is introduced in the context of classroom material. Many English teachers in Taiwan assume that by providing a definition in Chinese, examples, along with the pronunciation of a word to students (giving the IPA version), students can learn that word easily by themselves in the reading context. This fails to provide students with a method to learn and remember words. This contextual method does not, for example, teach students whether they should learn a word by the shape or by its sound; nor does it tell students how to memorize a word they have just learned. Because many Chinese students encounter a situation of learning through reading, they may eventually learn many words only in the written form; and the pronunciation of these words may never be memorized by some of the students. Since one of the most important learning strategies, the graphophonic one, is not available, Chinese students may have difficulty learning and remembering English vocabulary items very efficiently.

It seems reasonable to suggest that intensive reading is not the best way to introduce new vocabulary words to Chinese students because it is a poor guide to important phonological properties of words, such as graphophonic correspondences, the number of syllables, stress, and pronunciation. Furthermore, reading with all attention focused on meaning and no attention given to a word's form would not seem to be effective in aiding recall of words for productive use. This is proved by the common phenomenon that Chinese cannot carry on an English conversation after learning the language for more than six years. What is more, silent reading will definitively not help those second language learners who have difficulty understanding spoken English because they do not yet understand grapheme-phoneme connections. Nor will it help those learners 
who cannot be understood, not because they do not know the words, but because they cannot pronounce them correctly.

The fact that some students in this study knew graphophonic correspondences indicated that developing graphophonic awareness is possible for Chinese students even though their first language does not require that skill. Because most English teachers in Taiwan do not pay attention to students' development of graphophonic awareness, students are left to acquire this knowledge by themselves. Those who cling to the traditional Chinese method of rote learning without acquiring the knowledge of graphophonic correspondences in English may waste time and energy in learning English words. Accordingly, the knowledge of English grapheme-phoneme correspondences needs to be taught to EFL/ESL students, especially those whose first language is logographic such as Chinese.

\section{LIMITATIONS AND METHODOLOGICAL PROBLEMS}

The results probably only suggest that instruction of grapheme-phoneme correspondences may be helpful recalling and identifying a written word's meaning. Instruction in pronunciation appears less helpful for recalling written words recently learned. Perhaps pronunciation instruction only facilitates students in remembering and recognizing spoken words. The reason I chose written tests to measure students' vocabulary recall achievement is that pronunciation tests are not familiar to students in Taiwan. Moreover, a pronunciation test might not be a good way to measure Chinese students' performance in recalling vocabulary. Because they are not familiar with a pronunciation test, students may not pronounce an English word correctly while they do recall the word. Further research should be done to investigate how pronunciation instruction affects students' performance on speaking and listening to English words.

In addition, due to the time limitation, each test had only ten items. There was a possibility that students' performance was not measured appropriately because the number of questions was small. The better performance of the experimental group might result 
from guessing, since there were only 10 items, which were in a multiple-choice format. If it had been possible, this research would have done with more items to test students.

Furthermore, the curricula used to teach graphophonic correspondences were new and interesting to the students, and so the experimental group seemed to pay more attention in the class than the control group. Instruction in pronunciation did not particularly appeal to the students since it was not very different from the lessons they had previously had. Maybe this could be a variable which was not controlled in this study.

\section{SUGGESTIONS FOR FURTHER RESEARCH}

There are several questions that could be studied further. What kind of effect will the ability to pronounce sounds in English have on how well students apply the graphophonic strategy? Since the graphophonic strategy involves pronunciation to some extent, will the instruction of graphophonic correspondences cause anxiety if students have problems in pronouncing some English sounds? To figure out how many variables will affect Chinese students' vocabulary learning, further research could be done on the effectiveness of visual, rote-learning or extensive and intensive reading, either alone or compared with the graphophonic strategy by itself.

Since more pronunciation practice did not seem to help the control group perform better in this study, the results do not confirm Channell's claim that for second language learners semantic and phonological links would be the most helpful in facilitating the future recall of new vocabulary. Further research should be done on comparison among ESL/EFL learners, especially between Chinese, and those whose first language is not a logographic system. Could it be that the conclusions form this study can only be applied to those students whose first language is a logographic one? 


\section{REFERENCES}

Adams, M. J. (1990). Beginning to read: Thinking and learning about print. Cambridge, MA: MIT Press.

Balmuth, M. (1982). The roots of phonics: A historical introduction. New York: Teachers College Press.

Barnitz, J. G. (1982). Orthographies, bilingualism and learning to read English as a second language. The Reading Teacher, $\underline{35}, 560-567$.

Baron, J., \& Treiman, R. (1980). Use of orthography in reading and learning to read. In Kavanagh, J. F., \& Venezky, R. L. (Eds.), Orthography, reading, and dyslexia. Maryland: University Park Press.

Bialystok, E. (1991). Letters, sounds, and symbols: Changes in children's understanding of written language. Applied Psycholinguistics, 12, 75-89.

Byrne, B., \& Fielding-Barnsley, R. (1989). Phonemic awareness and letter knowledge in • the child's acquisition of the alphabetic principle. Journal of Educational Psychology, $\underline{81}, 313-321$.

Channell, J. (1988). Psycholinguistic considerations in the study of L2 vocabulary acquisition. In R. Carter and M. McCarthy (Eds.), Vocabulary and language teaching (pp 83-96). New York: Longman.

Chao, Y. R. (1968). A grammar of spoken Chinese. California: University of California Press.

Cheng, C. M. (1992). Lexical access in Chinese: Evidence from automatic activation of phonological information. In H. C. Chen \& O. J. L. Tzeng (Eds.), Language processing in Chinese (pp 67-91). The Netherlands: North-Holland.

Chomsky, N. \& Halle, M. (1968). The sound patterns of English.

New York: Harper and Row. 
Cummings, D. W. (1988). American English spelling.

Baltimore and London: The Johns Hopkins University Press.

Cunningham, A. E. (1990). Explicit versus implicit instruction in phonemic awareness. Journal of Experimental Child Psychology, 50, 429-444.

Fromkin, V., \& Rodman, R. (1988). An introduction to language.(4th ed.)

Orlando, Florida: Holt, Rinehart and Winston, Inc.

Garman, M. (1990). Psycholinguistics.

Cambridge: Combridge University Press.

Gleitman, L. R., \& Rozin, P. (1977). The structure and acquisition of reading I: Relations between orthographies and the structure of the language. In A. S. Reber \& D. L. Scarborough (Eds.), Toward a psyhology of reading. Hillsdale, NJ: Lawrence Erlbaum Associates.

Goldman, S. R., Hogaboam, T. W., Bell, L. C., \& Perfetti, C. A. (1980). Short-term retention of discourse during reading. Journal of Educational Psychology, 72, 647-655.

Goswami, U., \& Bryant, P. (1990). Phonological skills and learning to read. Hillsdale, NJ: Lawrence Erlbaum Associates.

Gough, P. B., \& Hillinger, M. L. (1980). Learning to read: An unnatural act. Bulletin of the Orton Dyslexia Society, 30, 179-196.

Griffith, P. L., \& Olson, M. W. (1992). Phonemic awareness helps beginning readers break the code. The Reading Teacher, 45 , 516-523.

Hanna, P. R. (1966). Phoneme-grapheme correspondences as cues to spelling improvment. Washington: U.S. Government Printing Office.

Heilman, A. W. (1993). Phonics in proper perspective. (7th ed.)

New York: Macmillan Publishing Company. 
Huang, C. (1992). The relationship between the use of graphophonic strategy and the success in English vocabulary learning for Chinese. Thesis for the degree of M.A. in TESOL. Portland State University.

Kenworthy, J. (1992). Teaching English pronunciation. (7th ed.) London and New York: Longman

Klima, E. (1972). How alphabets might reflect language. In J. F. Kavanaugh \& I. Mattingly (Eds.), Language by ear and by eye. Cambridge, Mass.: MIT Press.

Lapp, D., \& Flood, J. (1983). Teaching reading to every child. New York: Macmillan Publishing Co., Inc.

Lefevre, C. A. (1970). Linguistics, English, and the language arts. Boston: Allyn and Bacon.

Li, H. -T. (1977). The history of Chinese characters. Taipei, Taiwan: Lian-Jian.

Li, C. N., \& Thompson, S. A. (1981). Mandarin Chinese. Berkeley and L. A., California: University of California Press.

Liberman, I. Y., \& Shankweiler, D. (1979). Speech, the alphabet, and teaching to read. In L. B. Resnick \& P. A. Weaver (Eds.), Theory and practice of early reading, vol. 2 (pp. 109-134). Hillsdale, NJ: Lawrence Erlbaum Associates.

Morley, J. (1992). Rapid review of vowel and prosodic contexts: Improving spoken English. Ann Arbor, Michigan: The University of Michigan Press.

Morley, J. (1992). Intensive consonant pronunciation practice: Improving spoken English. Ann Arbor, Michigan: The University of Michigan Press.

Nunan, D. (1993). Research methods in language learning. (2nd ed.) Cambridge: Cambridge University Press

Osborne-Wilson, C., Sinatra, R., \& Baratta, A. N. (1989). Helping Chinese students in the literacy transfer process. Journal of Reading, 32, 330-336. 
Perfetti, C. A., Zhang, S., \& Berent, I. (1992). Reading in English and Chinese: Evidence for a "universal" phonological principle. In R. Frost and L. Katz (Eds.), Orthography, phonology, morphology, and meaning (pp 227-248).

Amsterdam, The Netherlands: North-Holland Elsevier Science Publishers B.V.

Perfetti, C. A., \& McCutchen, D. (1982). Speech processes in reading. In N. Lass (Ed.), Speech and language: Advances in basic research and practice (pp. 237-269). New York: Academic Press.

Prator, C. H., \& Robinett, B. W. (1985). Manual of American English pronunciation. (4th ed.) New York: Holt, Rinehart and Winston, Inc.

Rinsky, L. A., \& Griffith, B. (1978). Teaching word attack skills. Dubuque, Iowa: Gorsuch Scarisbrick, Publishers.

Sinatra, R. (1981). Using visuals to help the second language learner. The Reading Teacher, $\underline{35}$, 539-546.

Templeton, S. (1983). Using the spelling/meaning connection to develop word knowledge in older students. Journal of Reading, 27, 8-14.

Tzeng, O. J. L., \& Singer, H. (1978-1979). Failure of Steinberg and Yamada to demonstrate superiority of kanji over kana for initial reading instructions in Japan. Reading ResearchQuarterly, 14, 661-667.

Venezky, R. L. (1967). English orthography: its graphical structure and its relation to sounds. Reading Research Quarterly, 2, 75-105.

Venezky, R. L. (1970). The structure of English orthography The Hague: Mouton.

Wolfram, W., \& Johnson, R. (1982). Phonological analysis: Focus on American English. Englewood Cliffs, New Jersey: Prentice-Hall, Inc.

Yopp, H. K. (1992). Developing phonemic awareness in young children. The Reading Teacher, 45 , 696-703. 
Zhou, M. (1988). Script effects and reading strategies: Ideographic language readers vs. alphabetic language readers in ESL. Thesis for the degree of M.A. in TESOL. Portland State University. 
APPENDIX A

THE NON-WORD LIST 
APPENDIX A

THE NON-WORD LIST

1. tabe

2. fash

3. chuke

4. rasn't

5. lome

6. ketting

7. hud

8. satch

9. ekotion

10. hipe 
APPENDIX B

CURRICULA FOR THE CONTROL GROUP 
Time Line for the Control Group

1. The first class (two hours): the 15 English vowels (based on Improving Spoken English ${ }^{1)}$

2. The second class (two hours): more about the 15 English vowels (also based on Improving Spoken English)

3. The third class (three hours): the English consonant system (also based on Improving Spoken English)

4. The fourth class (two hours): consonant contrast (also based on Improving Spoken English)

5. The fifth class (three hours): the word stress rules (based on Teaching English Pronunciation $^{2}$ ) and the syllable structure (based on Improving Spoken English)

\footnotetext{
${ }^{1}$ Morley, J. (1992). Rapid review of vowel and prosodic contexts: Improving spoken English. Ann Arbor, Michigan: The University of Michigan Press.

2 Kenworthy, J. (1992). Teaching English pronunciation. (7th ed.) London and New York: Longman
} 


\section{LESSON PLAN C-1}

Class: Students are 18-19 years old. They are in their second year of junior college, and are now in a two-hour a week special class for pronunciation practice. This class is the control group in my study.

Teaching Objective: To teach students 15 English vowels.

Materials: Handouts of facial diagram and vowel chart.

Skills: Pronunciation.

Time: 2 class periods ( 1 hour each).

\section{Procedures:}

\section{Presentation}

a. Show students the facial diagram and discuss the different parts of the drawing with students.

b. Show students the vowel chart and explain the positions of the fifteen vowels: e.g. high front vowels, high back vowels, etc.

c. Compare vowel pairs: two high front vowels, $/ \mathrm{i} / / \mathrm{I} /$, two mid front vowels $/ \mathrm{e} / / \varepsilon /$, and two high back vowels, $/ \mathrm{u} / \mathrm{u} /$.

d. Present the front vowels: two high front vowels / i \& /I/, two mid front vowels /e/ $\& / \varepsilon /$ and one low front vowel /æ/.

e. Present the central vowels: one high central vowel $/ S^{\prime} /$, one mid central vowel $/ \mathrm{N} /$, and one low central vowel $/ a /$.

f. Present the back vowels: two high back vowels $/ \mathrm{u} / \& / \mathrm{u} /$, one mid back vowel /o/, and one low back vowel $/ 2 /$.

g. Present diphthongs: /aI/, /au/, and / $\mathrm{I} /$ /.

Teacher may give many examples of each vowel.

\section{Focused Practice}

\section{a. Listening and Feeling the Movements of Each Vowel}

Have students practice the vowels and concentrate on listening carefully, watching the teacher, and feeling the movements for each sound. Some of the pronunciation movements 
may seem strange since the English sounds are different from those in their first language. Teacher may remind them of the phonemes of their own language, but also points out differences between similar phonemes in the two languages.

b. Practicing Words for Each Vowel

\begin{tabular}{|c|c|c|c|c|c|}
\hline Vowel 1: /i/ & see & me & read & seem & easy \\
\hline Vowel 2: /I/ & it & win & did & him & river \\
\hline Vowel 3: /e/ & say & day & may & rain & able \\
\hline Vowel 4: /ع/ & yes & red & head & ten & ready \\
\hline Vowel 5: /æ/ & fat & add & bad & $\operatorname{man}$ & answer \\
\hline Vowel 12: |క̌| & bird & her & word & turn & service \\
\hline Vowel 6: IN & bus & fun & run & sun & study \\
\hline Vowel 7: |a/ & stop & job & Mom & John & college \\
\hline Vowel 8: /u/ & two & room & June & ruler & too \\
\hline Vowel 9: /U/ & books & good & wood & stood & cookie \\
\hline Vowel 10: /o/ & no & go & show & drove & open \\
\hline Vowel 11:/ / / & law & saw & song & $\operatorname{dog}$ & August \\
\hline Vowel 13:/aI/ & my & tie & wide & nine & decide \\
\hline Vowel 14:/au/ & cow & now & how & down & around \\
\hline Vowel $15: / \partial I /$ & boy & toy & noise & join & enjoy \\
\hline
\end{tabular}

\section{Follow Up}

Teacher may give students a great deal of practice in some sounds which they have problems pronouncing correctly. 


\section{Lesson Plan C-2}

Class: Students are 18-19 years old. They are in their second year of junior college, and are now in a two-hour a week special class for pronunciation practice. This class is the control group in my study.

Teaching Objective: To teach students more about 15 English vowels.

Materials: Handouts of facial diagram and vowel chart.

Skills: Pronunciation.

Time: 2 class periods ( 1 hour each).

\section{Procedures:}

\section{Presentation}

a. The Front Vowels

Let students practice two high front vowels: / $i /$ as in see, /I/ as in it. Let them repeat in the following way: see it and see it. Two mid front vowels: /e/ as in say, $/ \varepsilon /$ as in yes. Repeat: say yes and say yes. One low front vowel: $/ æ /$ as in fat. Repeat:fat fat. Repeat all the front vowels: $/ \mathrm{i} / \mathrm{I} / \mathrm{e} / \mathrm{/} / \mathrm{g} / \mathrm{/} /$ see it say yes fat.

b. The Central Vowels

Let students practice one high central vowel: $/ 5 /$ as in bird. Repeat: bird bird.

One mid central vowel: $/ \mathrm{N} /$ as in bus. Repeat:bus bus. One low central vowel:/a/ as in stop. Repeat:stop stop. Repeat all the central vowels: $/ 5 / / N / a /$ bird bus stop.

c. The Back Vowels

Let students practice two high back vowels: $/ \mathrm{u} /$ as in two and $/ \mathrm{v} /$ as in books. Repeat: two books two books. One mid back vowel: $/ O /$ as in no. Repeat: no no. One low back vowel: / $\mathrm{s} /$ as in law. Repeat: law law. Repeat all the back vowels: / $\mathrm{U} / \mathrm{J} / \mathrm{O} / \mathrm{O}$ $/ 2 /$ two books no law.

d. The Diphthongs

Let students practice the three diphthongs: /aI/ as in my, /av/ as in cow, / II/ as in boy. Repeat: my cowboy my cowboy. Repeat:/aI//aU//JI/ my cowboy. 


\section{Focused Practice}

a. Listening and Feeling the Movements of Each Vowel

Have students practice the vowels and concentrate on listening carefully, watching the teacher, and feeling the movements for each sound. Let students practice the front, central and back vowels, and diphthongs, and feel the differences among them.

b. More Practice

$\begin{array}{ll}\begin{array}{l}\text { Vowel /i/ } \\ \text { green }\end{array} & \text { I want a green tree. } \\ \text { tree } & \\ \text { three } & \text { I lost three keys. } \\ \text { keys } & \\ \text { read } & \text { Read each book. } \\ \text { each } & \end{array}$

Vowel /I/ this This isn't his.

isn't

his

which Which window?

window

Vowel /e/

take

Take it away.

away

today

eighth

May

Vowel / $\varepsilon /$

best

It's the best restaurant in town.

restaurant

ready

I'll be ready at ten-twenty.

ten

twenty

Vowel /æ/

happy

family

handsome

Today is the eighth of May.

man 
danced They danced and sang.

sang

Vowel / $/ 3 /$

learn

Learn ten new words.

words

her

Her skirt was purple.

skirt

purple

work I can work on Thursday.

Thursday

Vowel /N

study

I'll study on Monday.

Monday

cousin

coming

lunch

running

bus

My cousin is coming to lunch.

Vowel /a/

father

My father forgot.

forgot

college

October

College opens in October.

got

I got a spot on my collar.

spot

collar

Vowel /u/

new

She wants some new blue shoes.

blue

shoes

new

He's running to catch the bus.

group

students

two

fruit

We have a new group of students.

I want two bags of fruit.

Vowel /u/ took

Someone took my book. 
book

stood He stood on one foot.

foot

good She's a good cook.

cook

Vowel /o/

won't

I won't go.

go

sold

We sold the old stove.

old

stove

close

Please close the window.

window

Vowel / د/

lost

I lost my ball.

ball

across

It's across the hall.

hall

taught

He taught us a song.

song

long

How long was he gone?

gone

Vowel /aI/

nice

It's a nice night.

night

bright

There's a bright light in the sky.

light

sky

I

like

fly

Vowel /au/

down

Meet me down town in an hour.

town

hour

mouse

around

house

crowd

loud

I like to fly. 
Vowel / II/

noisy What a noisy toy.

toy

boy

The boy joined a coin club.

join

coin

joyous

What a joyous voice.

voice

\section{Follow Up}

Teacher may give students a great deal of practice in some sounds which they have problems pronouncing correctly. 


\section{Lesson Plan C-3}

Class: Students are 18-19 years old. They are in their second year of junior college, and are now in a two-hour a week special class for pronunciation practice. This class is the control group in my study.

Teaching Objective: To teach students 24 English consonants.

Materials: Handouts of facial diagram and consonant chart.

Skills: Pronunciation.

Time: 3 class periods ( 1 hour each).

\section{Procedures:}

\section{Presentation}

a. Show students the facial diagram and discuss the different parts of the drawing with students.

b. Show students place of articulation. The 24 consonant sounds of English can be divided into eight categories based on their place of pronunciation.

c. Show students the difference between voiced consonants and voiceless consonants.

\section{Focused Practice}

\section{a. Listening and Feeling the Movements of Each Consonant}

Have students practice the consonants and concentrate on listening carefully, watching the teacher, and feeling the movements for each sound. Some of the pronunciation movements may seem strange since the English sounds are different from those in their first language. The teacher may remind them of the phonemes of their own language, but also points out differences between similar phonemes in the two languages.

\section{b. Practicing Words for Each Consonant}

Notice that the sounds in the first three of these categories are formed in the front part of the mouth. 
lips (Labial Sounds)

$/ \mathrm{m} /$ my

/w/ we

$/ \mathrm{p} /$ paper

/b/ bed

Lower Lip to Upper Teeth (Labio-dental Sounds)

/f/ fifty

/v/ vote

$/ \theta /$ thank (voiceless th)

/ $/$ father (voiced $t h$ )

The place of articulation for the sounds in the next three consonant categories is a little farther back in the mouth.

Tongue Tip to Toothridge (Alveolar Sounds)

$/ \mathrm{n} /$ new

/l/ like

/s/ speak

/z/ zoo

$/ t /$ ten

/d/ dollar

Tongue to Front of Hard Palate (Alveo-palatal Sounds)

/j/ yellow

/J/ ship

$/ 3 /$ treasure

/t / cheap

/dj / jet

Tongue to Mid Part of Hard Palate (Palatal Sounds)

$/ \mathrm{r} /$ ring 
The place of articulation for the sounds in the last two consonant categories is in the back of the mouth or in the throat.

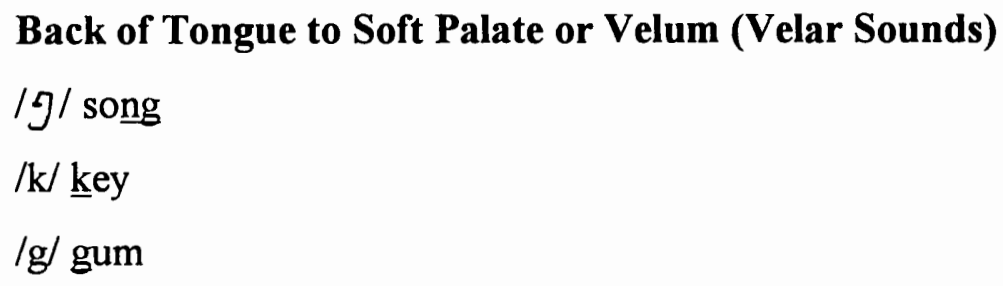

\section{Voicing}

Voiced consonant sounds have vibration at the voice box. Voiceless sounds lack this vibration and are therefore sometimes called whisper sounds. As shown below, English has eight pairs of voiced/voiceless sounds, one unpaired voiceless sound, and seven unpaired voiced sounds.

\begin{tabular}{llllllllll}
\hline Pairs & Voiceless & $/ \mathrm{f} /$ & $/ \theta /$ & $/ \mathrm{s} /$ & $/ \mathrm{s} /$ & $/ \mathrm{tg} /$ & $/ \mathrm{p} /$ & $/ \mathrm{t} /$ & $/ \mathrm{k} /$ \\
& Voiced/v/ & $/ \mathrm{v} /$ & $/ \mathrm{g} /$ & $/ \mathrm{z} /$ & $/ \mathrm{J} /$ & $/ \mathrm{d} j /$ & $/ \mathrm{b} /$ & $/ \mathrm{d} /$ & $/ \mathrm{g} /$
\end{tabular}

Unpaired Voiceless /h/

Unpaired Voiced $/ \mathrm{m} / \quad / \mathrm{n} / \quad / \mathrm{g} / \quad / \mathrm{w} / \quad / \mathrm{l} / \quad / \mathrm{j} / \quad \mid \mathrm{r} /$




\section{Lesson Plan C-4}

Class: Students are 18-19 years old. They are in their second year of junior college, and are now in a two-hour a week special class for pronunciation practice. This class is the control group in my study.

Teaching Objective: Consonant contrast.

Materials: Handouts of consonant contrast.

Skills: Pronunciation.

Time: 2 class periods (1 hour each).

\section{Procedures:}

\section{Presentation}

Show students the facial diagram and discuss the difference between each consonant contrast.

\section{Focused Practice}

\section{a. Listening and Feeling the Movements of Each Consonant Contrast}

Have students practice the consonant contrast and concentrate on listening carefully, watching the teacher, and feeling the movements for each sound and noticing the difference between each consonant contrast.

\section{b. Practicing Consonant Contrast}

$\begin{array}{ll}\begin{array}{l}\text { Contrast } 1 \\ \text { ten } / \mathbf{t} / \text { and thank } / \theta /\end{array} \\ \text { Column } 1 & \text { Column } 2 \\ \text { taught } & \text { thought } \\ \text { tick } & \text { thick } \\ \text { tanks } & \text { thanks } \\ \text { tin } & \text { thin } \\ \text { tie } & \text { thigh }\end{array}$


Contrast 2

$\begin{array}{ll}\text { city /s/ and thank / } \theta \text { / } & \\ \text { Column } 1 & \text { Column } 2 \\ \text { sick } & \text { thick } \\ \text { sank } & \text { thank } \\ \text { sin } & \text { thin } \\ \text { seem } & \text { theme } \\ \text { sinking } & \text { thinking } \\ \text { sing } & \text { think }\end{array}$

\section{Contrast 3}

dollar /d/ and father / $/$ /

Column 1

Column 2

day

they

dare

there

den

then

Dan

than

Dave

they've

doze

those

\section{Contrast 4}

like $N$ and ring $/ \mathbf{r} /$

Column 1

Column 2

lice

rice

lead

read

locks

rocks

lane

rain

lake

rake

load

road

low

row

\section{Contrast 5}

jet $/ d_{3} /$ and your $/ \mathbf{j} /$

Column 1

Column 2 


$\begin{array}{ll}\text { Jell-O } & \text { yellow } \\ \text { jail } & \text { Yale } \\ \text { joke } & \text { yoke } \\ \text { jet } & \text { yet } \\ \text { jam } & \text { yam } \\ \text { Jess } & \text { yes }\end{array}$

\section{Contrast 6}

ball $/ \mathrm{b} /$ and vote $/ \mathrm{v} /$

Column 1

Column 2

boat

vote

bent

vent

ban

van

bat

vat

berry

very

best

vest

\section{Contrast 7}

vote /v/ and we /w/

Column 1

Column 2

vine

wine

vent

went

verse

worse

vest

west

viper

wiper

vane

wane

\section{Contrast 8}

cheap $/ t \int /$ and shiny $/ \mathrm{f} /$

Column 1

Column 2

chair

share

chin

shin

chop

shop

cheap

sheep 
$\begin{array}{ll}\text { chopper } & \text { shopper } \\ \text { choose } & \text { shoes }\end{array}$

\section{Contrast 9}

city /s/ and shiny / $/$

Column 1

Column 2

Sue

shoe

suit

shoot

so

show

sock

shock

sop

shop

\section{Contrast 10}

cheap $/ t \int /$ and jet $/ d j^{\prime}$

Column 1

Column 2

cello

Jell-O

choke

joke

cheer

jeer

chess

Jess

cheap

jeep

chunk

junk

\section{Contrast 11}

\section{$z 00 / z /$ and father $/ \partial /$}

Column 1

Column 2

Zen

then

breeze

breathe

seize

seethe

close

clothe

ties

tithe

tease

teethe 


\section{Contrast 12}

like $/ /$ and ring $/ \mathbf{r} /$ (in initial consonant clusters)

Column 1

Column 2

climb

crime

clash

crash

clown

crown

clue

crew

glass

grass

glow

grow

\section{Contrast 13}

new /n/ and song $/ g /$

Column 1

Column 2

ran

rang

ban

bang

$\sin$

sing

thin

thing

win

wing

\section{Contrast 14}

paper /p/ and ball /b/

Column 1

Column 2

pill

bill

peas

bees

pin

bin

pear

bear

pouring

boring

pan

ban

\section{Contrast 15}

new /n/ and like / $/$

Column 1

Column 2

no low

night

light 
$\begin{array}{ll}\text { net } & \text { let } \\ \text { new } & \text { Lou } \\ \text { need } & \text { lead }\end{array}$

\section{Contrast 16}

fifty /f/ and paper /p/

Column 1

Column 2

feel

peel

fit

pit

face

pace

fair

pair

fast

past

fond

pond

\section{Contrast 17}

$\mathrm{my} / \mathrm{m} /$ and new /n/

Column 1

Column 2

sum

sun

warm

warn

dumb

done

tam

$\tan$

am

an

clam

clan

\section{Contrast 18}

fifty /f/ and thank / $\boldsymbol{\theta} /$

Column 1

Column 2

fin

thin

fought

thought

first

thirst

Fred

thread

free

three

offer

author 


\section{Contrast 19}

zoo /z/ and jet $/ d^{\prime} /$

Column 1

Column 2

zest

jest

zone

Joan

zip

gyp

czar

jar

reason

region

raising

raging 


\section{Lesson Plan C-5}

Class: Students are 18-19 years old. They are in their second year of junior college, and are now in a two-hour a week special class for pronunciation practice. This class is the control group in my study.

Teaching Objective: To teach students English word stress and syllable structure.

Materials: Handouts of generalizations relating to syllabication and stress.

Skills: Syllablizing English words and predicting the stress of English words.

Time: 3 class periods (1 hour each).

\section{Procedures:}

\section{Presenting Generalizations Relating to Syllabication}

Note: The syllable breaks for writing may not match the syllable breaks for pronunciation.

a. Every vowel sound in a word creates a syllable. So there are as many syllables as there are vowel sounds. Syllables are determined by the vowel sounds heard - not by the number of vowels seen.

Vowels seen

(4)
Vowels heard

b. Syllables divide between two consonants.
tar get
har bor
pic nic
gar den 
c. A single consonant between vowels usually goes with the second vowel.

$\begin{array}{llll}\text { fa mous } & \text { ho tel } & \text { di rect } & \text { ti ger } \\ \text { li mit } & \text { Eu rope } & \text { u nite } & \text { po lice } \\ \text { lo ca tion } & \text { va cant } & \text { sta di um } & \text { be hine }\end{array}$

d. As a general rule, do not divide consonant digraphs (ch, th, etc.) and consonant blends.

$\begin{array}{lll}\text { tea cher } & \text { wea ther ma chine se cret } \\ \text { bro ther } & \text { ath lete } & \text { coun try }\end{array}$

e. The word endings -ble, -cle, -dle, -gle, -kle, -ple, -tle, -zle form the final syllable

$\begin{array}{llll}\text { mar ble } & \text { mus cle } & \text { han dle } & \text { single } \\ \text { an kle } & \text { tem ple } & \text { puz zle } & \text { no ble }\end{array}$

f. Usually, prefixes and a number of suffixes form separate syllables.

$\begin{array}{llll}\text { re write } & \text { un fair } & \text { dis (a gree) ment } & \text { pre heat } \\ \text { hope less } & \text { un like ly } & \text { e quip ment }\end{array}$

\section{Using Parts of Speech to Predict Stress}

Many words in English have no systematic rules for stressed and unstressed syllables. Others have rules that are too complicated to be useful.

However, you can sometimes determine where stress falls in a word based on its part of speech. In other words, recognizing that a word is a noun, verb, adverb, or pronoun can sometimes help you know which syllable to stress.

\section{Rule 1-1}

There seems to be a very strong tendency in English for words described as core vocabulary to have stress on the first syllable. 
Front weight in nouns and adjectives

\begin{tabular}{|c|c|c|c|c|}
\hline & people & brother & table & father \\
\hline finger & 'woman & sister & ugly & p̀retty \\
\hline
\end{tabular}

Stress the first part of the compound noun deadline classroom software landlord

\section{Rule 1-2}

For noun + noun combinations, the stress often falls on the first noun or the stressed syllable of the first noun. air conditioner shoe store convention center

\section{Rule 1-3}

For reflexive pronouns, stress the -self or -selves syllable.

myself himself themselves

\section{Rule 1-4}

For numbers such as fourteen and forty, stress the -teen syllable.

thirteen years old/thirty years old sixteen dollars/sixty dollars

\section{Rule 1-5}

For verbs with a prefix as the first syllable, stress the second syllable, i.e. prefixes are not stressed in English words.

\begin{tabular}{|c|c|c|}
\hline outrun & repeat & begin \\
\hline overlook & increase & bec̀ause \\
\hline withdraw & distrust & exhaust \\
\hline overhear & infèr & prefer \\
\hline understand & confer & inspect \\
\hline conclude & invite & endange \\
\hline
\end{tabular}




\section{Rule 1-6}

For two-word verbs, stress the last or prepositional component.

print out shut down put off

\section{Rule 1-7}

For compound adverbs indicating location or direction, stress the second part of the compound in adverbs.

overs̀eas

downiown northìest

\section{Rule 1-8}

For words which can be used as both nouns and verbs, stress the first syllable in nouns (INsult) and the second syllable in verbs (inSULT).

\begin{tabular}{|c|c|c|c|}
\hline Noun & Verb & Noun & Verb \\
\hline record & record & upset & upset \\
\hline present & pres̀ent & recall & rec̀all \\
\hline project & project & checkout & check out \\
\hline object & object & turnover & turn òver \\
\hline survey & survey & handout & hand out \\
\hline s̀uspect & suspect & followup & follow ùp \\
\hline progress & prog̀ress & makeup & make ùp \\
\hline
\end{tabular}

\section{Using Suffixes to Predict Stress}

Like prefixes, suffixes are never stressed. But suffixes can be used to predict stress.

\section{Rule 2-1}

Stress the syllable before each of the following suffixes.

$\begin{array}{lll}\text {-ic } & \text {-ical } & \text {-ity } \\ \text { scientific } & \text { economical } & \text { publicity } \\ \text { electric } & \text { technological } & \text { electricity } \\ \text { spèific } & \text { neurological } & \text { humanity }\end{array}$




$\begin{array}{lll}\text {-ify } & \text {-ogy } & \text {-ion } \\ \text { personify } & \text { biòlogy } & \text { loc̀ation } \\ \text { simplify } & \text { psychology } & \text { competition } \\ \text { beautify } & \text { à̀logy } & \text { population } \\ \text {-meter } & \text {-graphy } & \\ \text { kilometer } & \text { phòtography } & \\ \text { parameter } & \text { biògraphy } & \end{array}$

There are other suffixes which have the same pattern:

-ive (impressive), -ian (median), -ious (delicious), -ish (diminish)

-ior (superior), -ible (impoossible), -iar (familiar).

\section{Rule 2-2}

Stress the syllable with each of the following suffixes, such as -ee, -eer, -ese, -esce, -esque and -ette.

refug̀ee, volunteer, Japañese, Chiñese, engineer, brunette

\section{Rule 2-3}

Approximately 1,000 English verbs end in -ate. The third syllable from the end should be stressed (Estimate). (The only time the stress shifts to another syllable is if -ion is added (estiMAtion).)

decorate

integrate

graduate

$$
\begin{aligned}
& \text { associate } \\
& \text { duplicate } \\
& \text { differentiate }
\end{aligned}
$$

separate
demonstrate
indicate

separate demonstrate indicate

\section{Middle Stress}

\section{Rule 3-1}

All the verbs ending in -ate have the main stress on the third syllable from the end, and also have a middle stress on the last syllable -ate. So -ate has the sound /et/, rather than /It/ or $/ 2 \mathrm{t} /$. 


\section{Rule 3-2}

A compound word has two independent parts. A compound word usually has main stress on the first part and middle stress on the second part. Dragnet is pronounced as /drægn $\varepsilon \mathrm{t} /$ while magnet is a simple word with main stress on the first syllable and an unstressed second syllable: /mægnat/. Vowels on the syllable with middle stress are not reduced to be a schwa $/ 2 /$. 
APPENDIX C

CURRICULA FOR THE EXPERIMENTAL GROUP 
Time Line for the Experimental Group

1. The first class (two hours): consonant pronunciation (based on Improving Spoken English ${ }^{1}$ )and graphophonic correspondences (based on Phonics in Proper Perspective ${ }^{2}$ and American English Spelling ${ }^{3}$ )

2. The second class (two hours): long vowels and short vowels in English orthography (based on Manual of American English Pronunciation ${ }^{4}$, American English Spelling and Teaching Word Attack Skills ${ }^{5}$ )

3. The third class (two hours): final unpronounced letter e, vowel digraphs and diphthongs, the letter y, and r-conditioned vowels (based on American English Spelling and Teaching Word Attack Skills)

4. The fourth class (two hours): the word stress rules (based on Teaching English Pronunciation $^{6}$ ) and the syllable structure (based on Improving Spoken English)

5. The fifth class (two hours): the connections between spelling, meaning and sound (based on "Using the spelling/meaning connection to develop word knowledge in older students 7 ") and the relationships between spelling, meaning and sound on a morphophonemic level.

\footnotetext{
${ }^{1}$ Morley, J. (1992). Intensive consonant pronunciation practice: Improving spoken English. Ann Arbor, Michigan: The University of Michigan Press

2 Heilman, A. W. (1993). Phonics in proper perspective. (7th ed.) New York: Macmillan Publishing Company.

3 Cummings, D. W. (1988). American English spelling. Baltimore and London: The Johns Hopkins University Press

${ }^{4}$ Prator, C. H., \& Robinett, B. W. (1985). Manual of American English pronunciation. (4th ed.) New York: Holt, Rinehart and Winston, Inc.

${ }^{5}$ Rinsky, L. A., \& Griffith, B. (1978). Teaching word attack skills. Dubuque, Iowa: Gorsuch Scarisbrick, Publishers.

${ }^{6}$ Kenworthy, J. (1992). Teaching English pronunciation. (7th ed.) London and New York: Longman.

7 Templeton, S. (1983). Using the spelling/meaning connection to develop word knowledge in older students. Journal of Reading, 27, 8-14.
} 


\section{Lesson Plan E-1}

Class: Students are 18-19 years old. They are in their second year of junior college, and are now in a two-hour a week special class for pronunciation practice and English graphophonic correspondences. This class is the experimental group in my study. Teaching Objective: To teach students all the consonants in English orthography. Materials: Handouts of facial diagram, consonant chart and spelling patterns of 24 consonants.

Skills: Pronouncing and associating graphemes with phonemes of all consonants.

Time: 2 class periods ( 1 hour each).

\section{Procedures:}

\section{Presentation}

a. Show students the facial diagram and discuss the different parts of the drawing with students.

b. Present the handout of the spelling patterns of all English consonants.

\section{Focused Practicea. Listening and Feeling the Movements of Each Consonant}

a. Have students practice the consonants and concentrate on listening carefully, watching the teacher, and feeling the movements for each sound. Some of the pronunciation movements may seem strange since the English sounds are different from those in their first language. The teacher may remind them of the phonemes of their own language, but also point out differences between similar phonemes in the two languages.

b. Have students associate the consonant letters with the sounds.

\section{Spelling Generalizations about Consonants}

\section{Single Consonant Letters}

The single consonant letters $b, d, f, h, j, k, l, m, p, r, t, v, w, y$, and $z$ are generally decoded as the following sounds: 

$\mathrm{b} / \mathrm{b} /$ boycott
$1 / 1 /$ limit
$t / t /$ tenant
$\mathrm{d} / \mathrm{d} /$ decorate
$\mathrm{m} / \mathrm{m} /$ mail
$\mathrm{v} / \mathrm{v} /$ very
$\mathrm{f} / \mathrm{f} /$ furnished
$\mathrm{n} / \mathrm{n} /$ native
$\mathrm{w} / \mathrm{w} /$ well
$\mathrm{h} / \mathrm{h} /$ huge
$\mathrm{p} / \mathrm{p} /$ price
y /j/ yellow
$\mathrm{j} / \mathrm{d} j /$ journal
$\mathrm{r} / \mathrm{r} / \mathrm{r}$ ent
$z / z / \underline{z} 00$

Note that the letters $w$ and $y$ function as consonants only when they appear as the initial letter in a syllable:

$y$ as $/ j /$ in yard, canyon, yawn, you, young, yellow

$\mathrm{w}$ as /w/ in walnut, went, war, wallow

\section{Consonants with More Than One Sound}

\section{The letter c}

c as $/ \mathbf{k} /$

cat, common, convenient

came, cold, compete

colony, condo, location $c$ as /s/ before e, $i, y$

city, ycle, specify

cent, peace, Greece

central, price, race

This pattern is used to capture the regular phonological alternation electric/electricity, plastic/plasticity.

\section{The letter $\mathrm{g}$}

$\mathrm{g}$ as $/ \mathrm{g} /$

gang, got, gum

gas, goat, gave

game, gold

(give as $/ g /$ and get as $/ g /$ are exceptions) g as / $d_{3} /$ before e, $\mathbf{i}, \mathbf{y}$

Egypt, huge, gym

gentlemen, ginger, genius

giraffe 
The letter $\mathbf{s}$

$\begin{array}{lll}\mathbf{s} \text { as /s/ } & \mathbf{s} \text { as /z/ } & \text { s as / / } \\ \text { Australia } & \text { his } & \text { assure } \\ \text { South Africa } & \text { games } & \text { sugar } \\ \text { university } & \text { reason } & \text { sure } \\ \text { spelling } & \text { use } & \end{array}$

\section{The letter q}

The consonant $q$ always appears with the vowel $u$. Together they represent the following sounds:

$q u$ as the / $\mathrm{k} /$ sound: antique, unique

$q u$ as the $/ \mathrm{kw} /$ sound: quarrel, quarter, queen, question, equipment

\section{The letter $\mathbf{x}$}

The letter $x$, like the letters $c$ and $q$, represents no sound of its own and is used to represent the following sounds:

$x$ as the $/ \mathrm{ks} /$ sound: fox, taxi, textbook

$x$ as the /gz/ sound: exist, exempt.

\section{Consonant Digraphs}

The unique $h$ digraphs

ch

chair / I

school $/ \mathrm{k} /$

chef / / gh

ghost /g/

laugh /f/

right /-//silent/ 
sh

ship $/ \int^{\prime}$ th

think $/ \theta /$

these $/ \partial /$ $\mathbf{w h}^{2}$

whom, who, whole $/ \mathrm{h} /$

what, why, which, when,

when $/ \mathrm{hw} /$ or $/ \mathrm{w} /$

Digraphs with a first silent letter

kn as /n/

knack

knee

knife

know wr as $/ \mathbf{r} /$

write

wrap

wrinkle

wrist ck as $/ \mathbf{k} /$

check

luck

truck

ticket ng as $/ \cap /$

ring

long

sing

king

Special combinations: dge and tch

dge as $\left|\dot{d}_{\gamma}\right|$

bridge

judge tch as $1 t f^{\prime}$

watch

stretch

Special combinations that decode as /バ

$\begin{array}{lll}\text { ci as } /, l & \text { ti as } / / / & \text { si as } / \zeta / \\ \text { artificial } & \text { location } & \text { permission } \\ \text { delicious } & \text { population } & \text { tension } \\ \text { special } & \text { station } & \text { mansion } \\ \text { clinician } & \text { initial } & \text { mis } \underline{\text { sion }}\end{array}$

Note that in initial position the grapheme ti precedes an unstressed vowel. Its phoneme here is $/ /$. This position and this value are extremely frequent. There are thousands of words ending in -tion whose ti has this phoneme $|f|$. However, if ti follows an $s$, the phoneme for the ti will be changed to $/ \operatorname{tg} /$, e.g. suggestion, question, Christian.

2 When o follows the wh digraph, this digraph decodes as $/ \mathrm{h}$. 


\section{Follow Up}

The students will have a great deal of practice in associating graphemes with phonemes and pronouncing sounds correctly. 


\section{LESSON PLAN E-2}

Class: Students are 18-19 years old. They are in their second year of junior college, and are now in a two-hour a week special class for pronunciation practice and English graphophonic correspondences. This class is the experimental group in my study Teaching Objective: To teach students "long vowels and short vowels in English orthography and the schwa / $/$ /.

Materials: Handouts of facial diagram, vowel chart and spelling patterns of five single vowel letters: $\boldsymbol{a}, \boldsymbol{e}, \boldsymbol{i}, \boldsymbol{o}$, and $\boldsymbol{u}$.

Skills: Pronouncing and associating graphemes with phonemes of long and short vowels.

Time: 2 class periods ( 1 hour each).

\section{Procedures:}

\section{Presentation}

a. Show students the facial diagram and discuss the different parts of the drawing with students.

b. Present the handout of the spelling patterns of "long" vowels and "short" vowels and unstressed vowel, the schwa / a/.

\begin{tabular}{|c|c|c|}
\hline Short Vowel Sound & Long Vowel Sound & Schwa Sound \\
\hline act $/ æ /$ & take /e/ & again / $/ 2 /$ \\
\hline elephant $/ \varepsilon /$ & even /i/ & ticket / $\Rightarrow /$ \\
\hline$\underline{\mathrm{it}} / \mathrm{I} /$ & ice /aI/ & pencil /a/ \\
\hline olive /a / & omen /o/ & obey /a/ \\
\hline until $/ N$ & unit $/ j u /$, rude $/ u /$ & nimbus /al \\
\hline
\end{tabular}

c. Present the spelling principles in the handout:

i. The letter $i$ tends to be associated with the short sound /I/ more often than the long sound /aI/.

\footnotetext{
* The classical way of explaining the spelling of English vowel sounds has involved dividing them into groups, called respectively the "long" vowels and the "short" vowels.
} 
ii. The letter $e$ tends to be associated with the short sound $/ \varepsilon /$ more often than the long sound /i/.

iii. The letter $a$ tends to be associated with the short sound /æ/ and the long sound /e/ with almost equal frequency.

iv. The letter $o$ tends to be associated with the short sound/a/ and the long sound /o/ with almost equal frequency.

$v$. The letter $u$ tends to be associated with the short sound $/ \mathrm{N}$ and the long sound $/ \mathrm{ju} /$ or $/ \mathrm{u} /$ with almost equal frequency.

d. Present other special single vowel sound patterns

$\begin{array}{llll}a \text { as } / a / & o \text { as } / \mathrm{u} / & o \text { as } / \supset / & u \text { as } / \mathrm{u} / \\ \text { father } & \text { lose } & \text { coffee } & \text { push } \\ \text { calm } & \text { whom } & \text { cloth } & \text { bullet } \\ \text { wad } & \text { move } & \text { soft } & \text { put }\end{array}$

\section{Focused Practice}

\section{a. Listening and Feeling the Movements of Each Vowel}

Have students practice the vowels and concentrate on listening carefully, watching the teacher, and feeling the movements for each sound. Some of the pronunciation movements may seem strange since the English sounds are different from those in their first language. Teacher may remind them of the phonemes of their own language, but also point out differences between similar phonemes in the two languages.

b. Let students practice the short sound and the long sound of the five single vowel letters and associate the vowel letters with the sounds.

\section{Spelling Generalizations about Single Vowels:}

a. Single vowel letters have a short and long sound. 
b. The short vowel sounds are /æ/ in act; / $/$ / in elephant; /I/ in it; / a/ in olive; and / $/$ in until.

c. The long vowel sounds are the same as the names of the vowel letters, $a / e /, e / i /$, $i / a \mathrm{I} /, \boldsymbol{o} / \mathrm{o} /, \boldsymbol{u} / \mathrm{j} \mathrm{u} /$. The letter $\boldsymbol{u}$ has a second additional long vowel sound of $/ u /$ in brute.

d. The letter $\boldsymbol{a}$ as / $\boldsymbol{a} /$ in calm; $\boldsymbol{o}$ as /u/ in prove; $\boldsymbol{o}$ as / $/ \mathrm{J}$ in soft and $\boldsymbol{u}$ as $/ \mathrm{J} / \mathrm{in}$ push have at least an additional sound.

e. Unstressed syllables with a single vowel letter may have a schwa sound. The sound is written as / $\partial /$ in again.

The sound correspondences of single vowel letters are as follows:

letter $a$

læ/ as in act

$\mathrm{le} /$ as in take

$\mathrm{la} /$ as in calm

letter $\boldsymbol{O}$

$|a|$ as in olive

$10 /$ as in omen

$\mathrm{lu} / \mathrm{as}$ in do

$/ \mathrm{J} /$ as in orange

$/ N /$ as in some letter $\boldsymbol{e}$

$/ \varepsilon /$ as in elephant

/i/ as in even letter $\boldsymbol{i}$

$/ \mathrm{I} /$ as in it

/aI/as ice letter $\boldsymbol{u}$

$/ N$ as in upp

$/ j u /$ as in unit

$\mathrm{l} u /$ as in rude

$/ \mathrm{u} /$ as in push

the schwa

$/ a /$ as in again

$/ \partial /$ as in fuel

$/ \partial /$ as in pencil

$/ \partial /$ as in second

$/ a /$ as in nimbus

\section{Follow Up}

The students will have a great deal of practice in associating graphemes with phonemes and pronouncing sounds correctly. 


\section{Lesson Plan E-3}

Class: Students are 18-19 years old. They are in their second year of junior college, and are now in a two-hour a week special class for pronunciation practice and English graphophonic correspondences. This class is the experimental group in my study. Teaching Objective: To teach students vowel digraphs and diphthongs, final unpronounced letter $e$, the letter $y$, and r-conditioned vowels.

Materials: Handouts of facial diagram, vowel chart and spelling patterns of these vowels.

Skills: Pronouncing and associating graphemes with phonemes of these vowels.

Time: 2 class periods ( 1 hour each).

\section{Procedures:}

\section{Presentation}

Present the spelling patterns of vowel digraphs and diphthongs, final unpronounced letter $e$, the letter y and $r$-conditioned vowels.

\section{Focused Practice}

Have students practice these vowel sounds and associate the spelling patterns of vowel digraphs and diphthongs with the sounds.

\section{Spelling Patterns for This Lesson}

Vowel Digraphs and Diphthongs

Vowel digraphs and diphthongs that begin with a

ai ay

au

aw

vailable /e/

stạ /e/

auto / / /

saw / / 
Vowel digraphs with e

\begin{tabular}{|c|c|c|c|c|}
\hline ee & ea & ie & ei & ey \\
\hline \multirow[t]{3}{*}{ sleep / i/ } & lease /i/ & believe / i/ & receive / $i /$ & key/i/ \\
\hline & bread / / / & tie /aI/ & vein /e/ & prey /el \\
\hline & break /e/ & & & \\
\hline
\end{tabular}

Vowel digraph with $\mathbf{i}$

igh as /aI/

bright, flight, right, light, high

Vowel digraphs/diphthongs with o

\begin{tabular}{|c|c|c|c|}
\hline \multirow{3}{*}{$\begin{array}{l}\text { oa } \\
\text { coat /o/ }\end{array}$} & 00 & ou & ow \\
\hline & food $/ u /$ & about /au/ & how /au/ \\
\hline & book /u/ & $\begin{array}{l}\text { cousin / } / \\
\text { shoulder /O/ } \\
\text { group /u/ } \\
\text { *bought / / }\end{array}$ & own $/ 0 /$ \\
\hline oi & oy & & \\
\hline oil / II/ & boy $/ \supset I /$ & & \\
\hline
\end{tabular}

Vowel diphthongs encoding /u/

ue

ui

ew

oo

blue /u/

suit $/ \mathrm{u} /$

blew $/ u /$

tooth /u/

due /u/

juice $/ \mathrm{u} /$

chew $/ u$ /

shoot $/ u /$

true /u/

juicy /u/

flew $/ u /$

food /ul 


\section{Final Unpronounced Letter e}

1. Final $e$ may indicate that the vowel before it is long

\begin{tabular}{|c|c|}
\hline $\begin{array}{l}\operatorname{mad} / æ / \\
\text { met / } / \varepsilon / \\
\text { rid /I/ } \\
\text { not / a/ } \\
\text { cut / } /\end{array}$ & $\begin{array}{l}\text { made /e/ } \\
\text { mete /i/ } \\
\text { ride /ai/ } \\
\text { note /o/ } \\
\text { cute / ju/ }\end{array}$ \\
\hline
\end{tabular}

2. Final $e$ may indicate that the preceding $c$ and $g$ have a soft sound as $/ \mathrm{s} /$ in $i \underline{c} e$ and $/ d z /$ in huge

3. Final $e$ is used after the letter $v$, as in have, give and love because English words do not end in $v$. (Sometimes, however, the final $e$ after $v$ does make the preceding vowel long in such words as shave and stove.)

\section{The Letter $y$}

y as a consonant at the beginning: $/ j /$ yard, yellow

$\mathbf{y}$ as a vowel in the middle of words: /I/ gym /aI/ cycle

y as a vowel at the end of words: /I/ pretty /aI/dry

$\mathbf{y}$ as part of the vowel digraph ay: /e/ may

$\mathbf{y}$ as part of the vowel digraph ey: /I/ valley

$\mathbf{y}$ as part of the diphthong oy: $\quad /$ / boy

\section{R-Conditioned Vowels}

\begin{tabular}{|c|c|c|c|c|}
\hline er & & & & \\
\hline her / $/ 3 /$ & first $/ 3 /$ & purchase $/ \Im /$ & carlarl & fork/ $/ \mathrm{rl}$ \\
\hline $\begin{array}{l}\text { here /Irl } \\
\text { *there / } / \varepsilon r /\end{array}$ & fire/aIrl & pure /jurl & care $/ \varepsilon r /$ & divorce / $/ \supset r /$ \\
\hline
\end{tabular}


Note that $e r, i r, u r$ are the major spellings of $/ 3^{7} \%$, but when such spellings occur on the unstressed syllable will be pronounced $|\not|$, a reduced $/ \zeta /$, e.g. father $|\not|$, popular $|\not|$, actor $/ 2 \%$.

\begin{tabular}{|c|c|c|c|c|}
\hline ear & eer & air & oar & our \\
\hline hear /Ir/ & beer /Ir/ & chair / ع r/ & roar /or/ & journal / $3 /$ \\
\hline $\operatorname{eard} \mid 3^{2} /$ & & & & tour/ur/ \\
\hline wear / $/ \varepsilon r /$ & & & & four lorl \\
\hline
\end{tabular}

heart $/ a r /$

wor $/ w 3 /$

worse

word

work

Note that when a vowel and $r$ are not in the same syllable, the vowel and the $/ r$ / have to be pronounced separately, e.g. bacteria, serious, hero, character, familiarity, area, orient, memorial.

\section{Follow Up}

The students will have a great deal of practice in associating graphemes with phonemes and pronouncing sounds correctly. 


\section{Lesson Plan E-4}

Class: Students are 18-19 years old. They are in their second year of junior college, and are now in a two-hour a week special class for pronunciation practice and English graphophonic correspondences. This class is the experimental group in my study. Teaching Objective: To teach students English word stress and syllable structure. Materials: Handouts of generalizations relating to syllabication and stress.

Skills: Syllablizing English words and predicting the stress of English words.

Time: 3 class periods ( 1 hour each).

\section{Procedures:}

\section{Presenting Generalizations Relating to Syllabication}

Note: The syllable breaks for writing may not match the syllable breaks for pronunciation.

a. Every vowel sound in a word creates a syllable. So there are as many syllables as there are vowel sounds. Syllables are determined by the vowel sounds heard - not by the number of vowels seen.

$\begin{array}{lcc} & \text { Vowels seen } & \text { Vowels heard } \\ \text { measure } & (4) & (2) \\ \text { moment } & (2) & (2) \\ \text { research } & (3) & (2) \\ \text { write } & (2) & (1) \\ \text { native } & (3) & (2) \\ \text { receive } & (4) & (2)\end{array}$

b. Syllables divide between two consonants.

tar get har bor pic nic gar den 
c. A single consonant between vowels usually goes with the second vowel.

$\begin{array}{llll}\text { fa mous } & \text { ho tel } & \text { di rect } & \text { ti ger } \\ \text { li mit } & \text { Eu rope } & \text { u nite } & \text { po lice } \\ \text { lo ca tion } & \text { va cant } & \text { sta di um } & \text { be hine }\end{array}$

d. As a general rule, do not divide consonant digraphs (ch, th, etc.) and consonant blends.

$\begin{array}{lll}\text { tea cher } & \text { wea ther } & \text { ma chine } \\ \text { bro ther } & \text { ath lete } & \text { coun try }\end{array}$

e. The word endings -ble, -cle, -dle, -gle, -kle, -ple, -tle, -zle form the final syllable

$\begin{array}{llll}\text { mar ble } & \text { mus cle } & \text { han dle } & \text { single } \\ \text { an kle } & \text { tem ple } & \text { puz zle } & \text { no ble }\end{array}$

f. Usually, prefixes and a number of suffixes form separate syllables.

$\begin{array}{llll}\text { re write } & \text { un fair } & \text { dis (a gree) ment } & \text { pre heat } \\ \text { hope less } & \text { un like ly } & \text { e quip ment }\end{array}$

\section{Using Parts of Speech to Predict Stress}

Many words in English have no systematic rules for stressed and unstressed syllables. Others have rules that are too complicated to be useful.

However, you can sometimes determine where stress falls in a word based on its part of speech. In other words, recognizing that a word is a noun, verb, adverb, or pronoun can sometimes help you know which syllable to stress.

\section{Rule 1-1}

There seems to be a very strong tendency in English for words described as core vocabulary to have stress on the first syllable. 
Front weight in nouns and adjectives

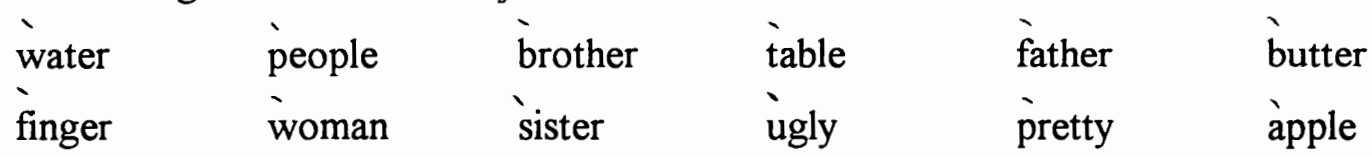

Stress the first part of the compound noun

deadline classroom software landlord

\section{Rule 1-2}

For noun + noun combinations, the stress often falls on the first noun or the stressed syllable of the first noun.

àr conditioner shoe store convention çenter

\section{Rule 1-3}

For reflexive pronouns, stress the -self or -selves syllable.

myself hims̀elf themselves

\section{Rule 1-4}

For numbers such as fourteen and forty, stress the -teen syllable.

thirteen years old/thirty years old sixteen dollars/sixty dollars

\section{Rule 1-5}

For verbs with a prefix as the first syllable, stress the second syllable, i.e. prefixes are not stressed in English words.

$\begin{array}{lll}\begin{array}{ll}\text { outrun } \\ \text { overlook }\end{array} & \begin{array}{l}\text { repeat } \\ \text { increase }\end{array} \\ \text { withdraw } & \text { distrust } & \text { bec̀ause } \\ \text { overhear } & \text { infer } & \text { exhaust } \\ \text { understand } & \text { confer } & \text { prefer } \\ \text { conclude } & \text { invite } & \text { inšpect } \\ & \text { endanger }\end{array}$




\section{Rule 1-6}

For two-word verbs, stress the last or prepositional component.

print out shut down put off

\section{Rule 1-7}

For compound adverbs indicating location or direction, stress the second part of the compound in adverbs.

overseas downtown northwest

\section{Rule 1-8}

For words which can be used as both nouns and verbs, stress the first syllable in nouns (INsult) and the second syllable in verbs (inSULT).

\begin{tabular}{|c|c|c|c|}
\hline Noun & Verb & Noun & Verb \\
\hline record & record & upset & upset \\
\hline present & present & recall & reçall \\
\hline project & project & checkout & check out \\
\hline òbject & object & turnover & turn over \\
\hline survey & survey & handout & hand out \\
\hline suspect & suspect & followup & follow up \\
\hline progress & prog̀ress & makeup & make ùp \\
\hline
\end{tabular}

\section{Using Suffixes to Predict Stress}

Like prefixes, suffixes are never stressed. But suffixes can be used to predict stress.

\section{Rule 2-1}

Stress the syllable before each of the following suffixes.

$\begin{array}{lll}\text {-ic } & \text {-ical } & \text {-ity } \\ \text { scientific } & \text { ecònomical } & \text { publicity } \\ \text { electric } & \text { technological } & \text { electricity } \\ \text { spècific } & \text { neurological } & \text { humanity }\end{array}$




$\begin{array}{lll}\text {-ify } & \mathbf{- o g y} & \text {-ion } \\ \text { personify } & \text { biòlogy } & \text { loc̀ation } \\ \text { simplify } & \text { psychology } & \text { compètition } \\ \text { b̀̀eautify } & \text { à̀ology } & \text { population } \\ \text {-meter } & \text {-graphy } & \\ \text { kilometer } & \text { phò̀ography } & \\ \text { parameter } & \text { biògraphy } & \end{array}$

There are other suffixes which have the same pattern:

-ive (imp̀ressive), -ian (median), -ious (delicious), -ish (diminish)

-ior (superior), -ible (imp̀ossible), -iar (familiar).

\section{Rule 2-2}

Stress the syllable with each of the following suffixes, such as -ee, -eer, -ese, -esce, -esque and -ette.

refug̀ee, volunteer, Japaǹese, Chinese, engineer, brunette

\section{Rule 2-3}

Approximately 1,000 English verbs end in -ate. The third syllable from the end should be stressed (Estimate). (The only time the stress shifts to another syllable is if -ion is added (estiMAtion).)

decorate

integrate

graduate

$$
\begin{aligned}
& \text { associate } \\
& \text { duplicate } \\
& \text { differentiate }
\end{aligned}
$$

separate
demonstrate
indicate

separate

demonstrate

indicate

\section{Middle Stress}

\section{Rule 3-1}

All the verbs ending in -ate have the main stress on the third syllable from the end, and also have a middle stress on the last syllable -ate. So -ate has the sound /et/, rather than IIt/ or /at/. 


\section{Rule 3-2}

A compound word has two independent parts. A compound word usually has main stress on the first part and middle stress on the second part. Dragnet is pronounced as /drægnet/ while magnet is a simple word with main stress on the first syllable and an unstressed second syllable: /mægnat/. Vowels on the syllable with middle stress are not reduced to be a schwa $/ \partial /$. 


\section{Lesson Plan E-5}

Class: Students are 18-19 years old. They are in their second year of junior college, and are now in a two-hour a week special class for pronunciation practice and English graphophonic correspondences. This class is the experimental group in my study. This class is the experimental group in my study.

Teaching Objective: To teach students connections between spelling, meaning, and sound in English orthography.

Materials: Handouts of prefixes, suffixes, and roots, alternation patterns in related words.

Skills: Pronouncing and associating the words with their spelling and meaning.

Time: 3 class periods ( 1 hour each)

\section{Procedures:}

\section{Presentation}

a. Make students become aware that for purposes of spelling, sound is not the most important feature; rather, meaning is. Demonstrate this by showing them silent/sounded consonants in related words.

b. Represent the sound level of the spelling/meaning connection by showing students absorbed or assimilated prefixes.

c. Show students alternation patterns in related words.

d. Show students roots and combining forms.

\section{Focused Practice}

\section{Silent/Sounded Consonants in Related Words}

The following patterns are cited from Shane Templeton's research (1983, p. 9-14). The $\boldsymbol{g}$ in sign and the $\boldsymbol{n}$ in solemn and autumn cause confusion. Investigating the phenomenon of these silent consonants is an excellent way to lead students to a meaning-based understanding of English spelling. Sign is considered along with signal and signature; solemn is considered along with solemnity and solemnize. Consonants that are silent in 
one word are often sounded in related words. The spelling/meaning connection thus helps dispel confusion over silent consonants by considering words in which they occur not as individual items but as members of larger groups that share common meaning and spelling features.

column

columnar

columniation

bomb

bombard

bombardment solemn

solemnity

solemnize

sign

signal

signature

signalize

( $g$ in signer is still silent) damn

damnable

damnation

damnatory

Note that $\mathbf{g}$ remains silent in design, designer, and $\boldsymbol{b}$ remains silent in doubt, doubtful, doubtless, debt, debtor.

\section{Absorbed or Assimilated Prefixes}

To get a feel for what occurs in prefix assimilation, try pronouncing in + mobile ("inmobile") rapidly. The sound that the letter $\mathrm{n}$ represents becomes absorbed or assimilated into the sound $\mathrm{m}$ represents. Eventually, the spelling of the prefix came to represent this change in sound; the spelling $n$ in $i n$ - changed depending on the first letter of the base or root word to which it was attached.

This phenomenon of absorbed or assimilated prefixes presents a potential spelling problem unless meaning is used to explain the double consonant spelling. In the following words, double consonants occur at the point where a prefix has been assimilated, yet only one consonant sound is heard. For each group of words, note both the original spelling of the prefix and how it has changed: ad- ("to" or "toward")—account, assume, approve; in- 


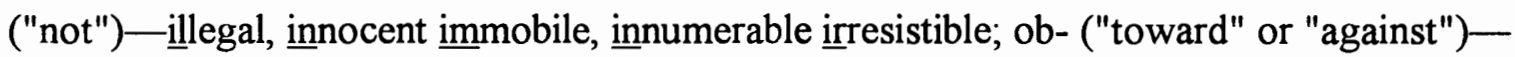
occur, oppose.

\section{Alternation Patterns in Related Words}

The patterns that are discussed here are grouped under a very general category that will be referred to as vowel alternation. This term is used because words that are related in meaning undergo changes in the pronunciation of their vowels.

- Pattern 1 Long vowel : short vowel alternation. Sample pairs are grave/gravity, sane/sanity, divinne/divininity, serene/serenity, cone/conic, produce/prodụction.

The italicized letters in each pair highlight the part of each word in which the spelling remains the same but the sound of the vowel in the accented syllable has changed or alternated from long to short. Like the silent consonant patterns discussed earlier, this vowel alternation pattern emphasizes that words related in meaning are often spelled similarly, despite changes in pronunciation. It is not enough to talk to students only about changing vowel sounds within these word pairs; the meaning connection must also be addressed explicitly.

\section{- Pattern 2 Long or short vowel : schwa alternation.}

define/definition, compete/competition, compose/composition local/locality, metall/metallic, relative/relativity, mobile/mobility

In each of these word pairs, the long vowel in the first word changes to a schwa $/ \partial /$ in the second word, although the spelling does not change. This pattern of alternation is often referred to as one type of vowel reduction because the accented long vowel in the first word of each pair becomes reduced or unaccented in the second word. 
Because the schwa is an unaccented, reduced vowel, its spelling is often a problem for students-its sound offers no clue to its spelling. Students, therefore, should be led to an extremely useful strategy: When they are uncertain about the spelling of the schwa sound in a word such as composition, they should try to think of a related word in which the corresponding vowel is apparent-as in the case with compose.

\section{- Pattern 3 Vowel and spelling alternation}

The words that fall into this category again alternate a long vowel to either a short or a reduced vowel, but there is an alternation in spelling as well, usually affecting the root of the word. The key to understanding these patterns lies in their predictability. Looking only at one pair, students can see no pattern; it is only when groups are considered that the logic emerges.

Note the pattern in each of the following groups of word pairs: (1) consume/consumption, assume/assumption, presume/presumption; (2) receive/reception, deceive/deception, conceive/conception; (3) explain/explanation, proclaim/proclamation. The meaning of the root does not change despite changes in sound and spelling. These patterns are less frequent, but they are not irregular.

The following patterns involve quite different sound alternations, but students are often fascinated to discover that the same root exists in both words of each pair: denounce/denunciation, pronounce/pronunciation, detain/detention, retain/retention, contain/contention.

\section{Roots and Combining Forms}

The problem is that Latin roots are often hidden within words and are difficult to locate. For example, attraction offers intriguing possibilities for analysis, but beginning an examination of Latin roots with examples such as -tract- is probably leaping a few 
conceptual notches. The root is hidden from the untrained student eye and, although its meaning changes subtly across words while retaining the core meaning of "to pull," students usually cannot appreciate this phenomenon. The Greek number prefixes mono-, bi-, tri-, quad-, and so forth are a good starting point because of their frequency.

For example, students are often surprised to note how the prefix mono- has affected the meaning of common words: monotone, monotonous, and monorail. It is a fairly short step to more intriguing forms such as tele-, thermo-, photo-, -meter, astro-. As such forms occur in different words, their pronunciation will change; this is quite natural and underscores the primacy of meaning over sound in English orthography. For example, students will note the changes in the pronunciation but not in the spelling of the italicized vowel letters as the stress shifts in the words telegraphy/telegraphic, thermometer/thermodynamic, photography/photographic.

Once students understand the way Greek combining forms work within words, they are ready for the challenge of Latin roots. It should be understood that the instructional objective here is not mastery of 157 Latin roots, but rather (1) a working understanding of a few relatively frequent roots and, perhaps, more important, (2) a sense of the root as a stable element in words, an element that can be conceptualized as a unit in the same way as are prefixes and suffixes.

It is wise to begin systematic study with roots whose one meaning in most words is relatively constant. The following is a sampling of frequent roots (Becker, Dixon, and Anderson-Inman, 1980) whose meanings are fairly stable:

-spect-: to look; inspect, spectator

-press-: to press; impress, pressure

-form-: shape; formula, conform

-port-: to carry; export, portable

-pose-: to put or place; compose, position 
-tract-: draw or pull; tractor, retract

-spir-: to breathe; respiration, inspire

Let's consider how one such root, -port-, might be investigated. When combined with prefixes and suffixes, its various meanings are easily perceived: port + able $=$ capable of being carried; port + er $=$ one who carries; im + port $=$ to carry into; $\mathrm{ex}+$ port $=$ to carry out of. By itself, of course, the root port has come to mean a harbor, or a place where cargoes are carried in and out.

\section{Follow Up}

The students will have a great deal of practice in associating graphemes with phonemes and pronouncing sounds correctly. 
APPENDIX D

THE VOCABULARY LEARNING LIST 


\section{APPENDIX D}

\section{THE VOCABULARY LEARNING LIST}

1. journal [ $d \hat{z} \hat{z} n !] n$. a magazine that is published regularly 期刊, 雜志 * His paper was published in a famous journal.

2. textbook ['tekst,buk] $n$. a book used in schools 教科書

* Students must bring their textbooks to school.

3. abbreviate [ə̀brivI,et] v.t. make a word, phrase, or story shorter; shorten 縮短; 縮寫

abbreviation $n$.

* We can abbreviate "foot" to "ft."

4. stadium ['́tedIam] $n$. a modern sports field 體育場; 運動場

* The race will take place at the new stadium.

5. popular ['papjaloy adj. liked by many people 受歡迎的 popularly $a d v$. popularity $n$.

* The movie star is popular with girls.

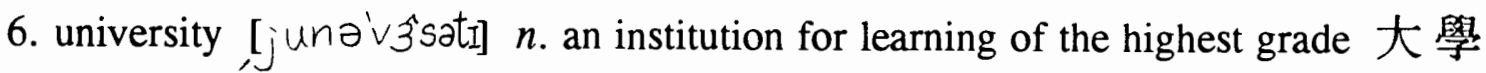
* This is a national university.

7. convenient [kən'vinjent] adj. causing no trouble; handy; easy to reach or use 便利的; 方便的

conveniently $a d v$. convenience $n$.

* It is convenient for us to go from here to the station.

8. equipment [I'kWIpmant] $n$. the things needed to do things 裝備; 設備 equip $v$.

* I think we need some modern office equipment. 
9. amateur [æmə, tjur] adj. a person who studies an art or plays a game for pleasure, not for money 業余者; 業余運動員

* He is not professional; he is only amateur.

10. compete [kəm'pit] v.i. enter a contest; try to win 比賽; 競賽 competition $n$.

* I don't want to compete with you in the race.

11. utility [ju'tIlatI] $n$. any useful service for the public, such as water to the home, the gas service, etc.

（如供應水、電、瓦斯等的）公用事業

* If you pay three thousand dollars a month, utilities will be included in the rent.

12. available [ $\gamma^{\prime} v e l a b \mid$ ] adj. that can be obtained, ready or suitable for use avail $v$. availability $n$. 可得到的; 可利用的

* This book is available in our library.

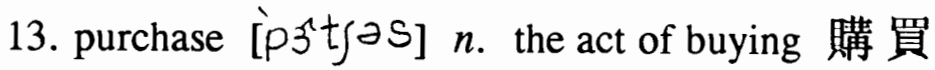
purchase $v$. purchasable adj.

* He gave his son some money for the purchase of a new dictionary.

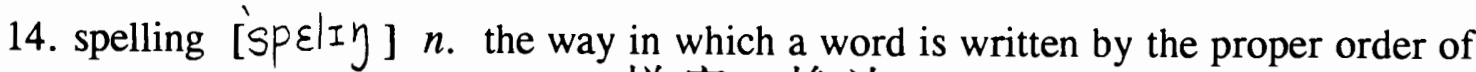
letters 拼字; 拼法

spell $v$.

* He is not good at spelling.

15. advertisement [æedvð'taIzmant] $n$. the act of making something generally known by means of printed matter, radio, or the like 廣告

* We all saw the advertisement on TV yesterday.

16. furnished [ $\left.f 3^{r} n I f t\right]$ adj. with furniture 借有家具的 furnish $v$. furniture $n$.

* This apartment is furnished.

17. condominium [ Kandə̀mInIJm] n. a block of apartments of which each is owned by the people wholive in it. 持分公寓

* They have just bought a condominium. 
18. colony ['kalonI] $n$. a country or area under the control of a distant country and settled by people from that country 殖民地

* Vietnam was once a French colony.

19. artificial [arto'fIjol] adj. made by human skill or art 人工的; 人造的 * The material is artificial, not natural.

20. international [Intzinæe $\partial n \mid$ ] adj. between or among nations 國際的 * English is an international language.

21. medal ['med!] $n$. a coinlike piece of metal, marked with a design or words, given as a reward or honor, or for celebrating a great event 獎章; 勛章

* The committee awarded him a gold medal.

22. solve [salv] v.t. find the answer to or explanation of something 解答; 解決 solution $n$.

* Can you solve the problem for me, please?

23. official [ $\left.\partial^{\prime} f_{I} \int \partial \mid\right]$ adj. of an office or a position of authority 官方的 * Mandarin is both our national language and official language.

24. maintenance ['mentanans] $n$. the act of maintaining 保飬 maintain $v$.

* The cost of maintenance of the car is high.

25. tenant [tEnant] $n$. a person who pays rent for the use of a room, or land etc. 房客; 佃戶

* We have 35 tenants in this building.

26. decorate [dgka, ret] v.t. make something beautiful 裝 飾 decoration $n$.

* We decorate the room with flowers.

27. billion [bIjjan] $n$. one thousand million 十億

* There are more than one billion Chinese people in the word. 
28. powerful [pavərfal] adj. strong; having great force 強大的; 有力的 power $n$.

* The United States is a powerful nation.

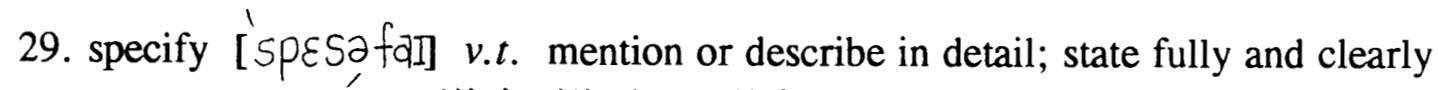
詳細説明; 詳記

specific adj. specifically $a d v$. specification $n$.

* Please specify the details of the operation.

30. athlete [élit] $n$. a person who is trained for games or sports 運動員; 運動家

* Tom is an excellent athlete; he is good at sports and games. 
APPENDIX E

THE SHORT-TERM AND LONG-TERM VOCABULARY RECALL TESTS 
The Short-Term Vocabulary Recall Test

Please choose the most suitable word to complete each sentence and put the answer, $a, b$, c, or $d$ in the ( ).

( ) 1. A is a magazine that is published regularly.
(a) journal
(b) research
(c) length
(d) location

( ) 2. Michael Jackson is a(n) star.
(a) central
(b) popular
(c) official
(d) artificial

( ) 3. Please bring me a cup of tea if it is
(a) convenient
(b) international
(c) official
(d) professional

( ) 4. The boys with each other in the race.
(a) maintain
(b) decorate
(c) compete
(d) advertise

( ) 5. When will the book be in our library?
(a) artificial
(b) powerful
(c) official
(d) available 
( ) 6 . is always a problem to every learner when he or she is learning English.
(a) Textbook
(b) Maintenance
(c) Spelling
(d) Decoration

( ) 7. We are looking for a(n) apartment.
(a) competed
(b) furnished
(c) boycotted
(d) abbreviated

( ) 8. I like flowers, but not ones.
(a) artificial
(b) official
(c) powerful
(d) journal

( ) 9. He won a gold in the Olympic Games.
(a) length
(b) medal
(c) lease
(d) peace

( ) 10. The teacher the problem for me.
(a) decorated
(b) competed
(c) united
(d) solved 
The Long-Term Vocabulary Recall Test

Please choose the most suitable word to complete each sentence and put the answer, $a, b, c$, or $d$ in the ( ).

( ) 1. Mr. Smith is our landlord; we are his
(a) athletes
(b) tenants
(c) amateurs
(d) students

( ) 2. Mainland China has a huge population, near more than one people.
(a) million
(b) trillion
(c) billion
(d) thousand

( ) 3. "Mr." is a(n) of "Mister".
(a) decoration
(b) population
(c) advertisement
(d) abbreviation

( ) 4 . will be included in the rent.
(a) possibilities
(b) utilities
(c) abilities
(d) universities

( ) 5. They Christmas trees at Christmas.
(a) decorate
(b) abbreviate
(c) unite
(d) furnish 
( ) 6. Proper to be in good condition. is important for the machines
(a) convenience
(b) importance
(c) maintenance
(d) abbreviation

( ) 7. Only athletes can compete in the Olympic Games. They cannot play sports as their occupation.
(a) professional
(b) amateur
(c) convenient
(d) common

( ) 8. He is engaged in business, so he has to travel all around the world.
(a) central
(b) convenient
(c) native
(d) international

( ) 9. We have to put a(n) in the newspaper for someone suitable for this job.
(a) advertisement
(b) maintenance
(c) abbreviation
(d) equipment

( ) 10. Hong Kong has been an English China will take it back in 1997.
(a) colony
(b) company
(c) cookery
(d) convoy but 
APPENDIX F

WORD LIST OF THE PRONUNCIATION TEST 
APPENDIX $\mathrm{F}$

WORD LIST OF THE PRONUNCIATION TEST

1. journal

2. popular

3. convenient

4. compete

5. available

6. spelling

7. furnished

8. artificial

9. medal

10. solved 
APPENDIX G

INFORMED CONSENT FORM 


\section{Informed Consent Form}

I, students learn English vocabulary.

, agree to take part in the research project on how Chinese

I understand that the study may involve up to three activities as follows:

1) Oral evaluation before a learning session-it will take each person 3-5 minutes.

2) Learning session-it will be 2 hours a week for 6 weeks.

3) Vocabulary recall evaluation after the learning session-one class will be scheduled for it.

I may not receive any direct benefit from taking part in this study. However, the study may help to increase knowledge that could contribute to an improved method of teaching English to Chinese students in the future. Li-ching Lin has offered to answer any questions I have about the study and what I am expected to do.

Li-ching Lin has promised that all information I give will be kept confidential to the extent permitted by law, and that the names of all people in the study will remain confidential.

I understand that I do not have to take part in this study. My decision to participate or not to participate in the study will not affect my official relationship with my teacher and my school, and will not affect my course grade for the English class, either. Further, I may withdraw my consent at any time.

I understand that there are no expected risks to me, but if at a later date I either experience problems as result of my participation, or have further questions concerning my participation, I may contact Li-ching Lin at (04) 339-5087 (Taichung, Taiwan), or at 0021-503-2224025 (Portland, Oregon, USA)

I have read and understand the above information and agree to take part in this study.

Date

Signature

If you have concerns or questions about this study, please contact the Chair of the Human Subjects Research Review Committee, Office of Research and Sponsored Projects, 105 Neuberger Hall, Portland State University, Oregon, USA 002-1-5037253417. 